\title{
Compilation of Earthquakes from 1850- 2007 Within 200 Miles of the Idaho National Laboratory
}

N. Seth Carpenter

July 2010

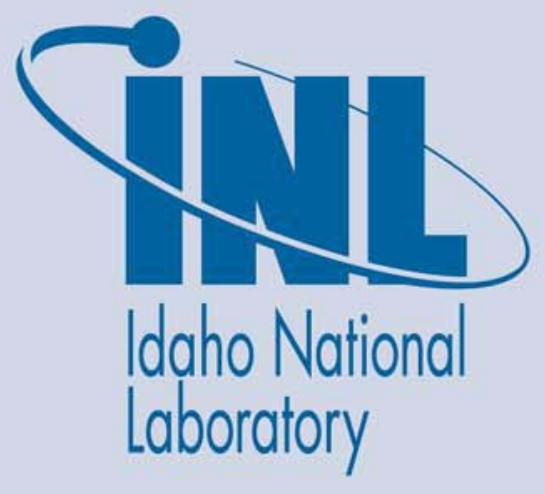

The INL is a U.S. Department of Energy National Laboratory operated by Battelle Energy Alliance 


\section{DISCLAIMER}

This information was prepared as an account of work sponsored by an agency of the U.S. Government. Neither the U.S. Government nor any agency thereof, nor any of their employees, makes any warranty, expressed or implied, or assumes any legal liability or responsibility for the accuracy, completeness, or usefulness, of any information, apparatus, product, or process disclosed, or represents that its use would not infringe privately owned rights. References herein to any specific commercial product, process, or service by trade name, trade mark, manufacturer, or otherwise, does not necessarily constitute or imply its endorsement, recommendation, or favoring by the U.S. Government or any agency thereof. The views and opinions of authors expressed herein do not necessarily state or reflect those of the U.S. Government or any agency thereof. 


\title{
Compilation of Earthquakes from 1850-2007 Within 200 Miles of the Idaho National Laboratory
}

\author{
N. Seth Carpenter
}

July 2010

Idaho National Laboratory

Structural and Seismic Analysis Department

Idaho Falls, Idaho 83415

http://www.inl.gov

Prepared for the

U.S. Department of Energy

Office of Nuclear Energy

Under DOE Idaho Operations Office

Contract DE-AC07-05ID14517 



\section{ACKNOWLEDGEMENTS}

I appreciate the support from Suzette Payne, Michael Stickney, Jim Pechmann, Jamie Farrell, Fabia Terra, and Amy Wright and the reviews provided by Richard Lee, Los Alamos National Laboratory and Ivan Wong, URS

Corporation. The U. S. Department of Energy (DOE), Office of Nuclear Energy, Science, and Technology funded this work under DOE Idaho Field Office

Contract DE-AC07-05ID14517. 


\section{CONTENTS}

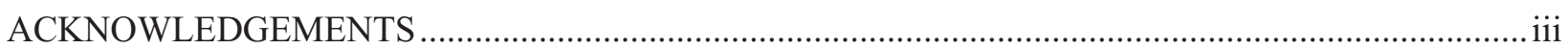

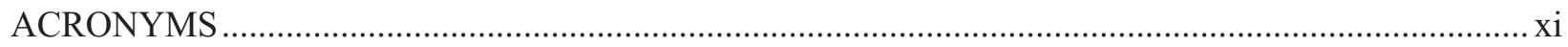

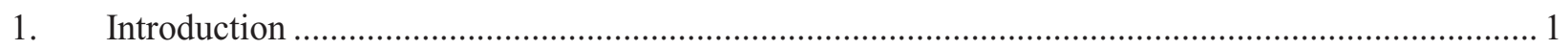





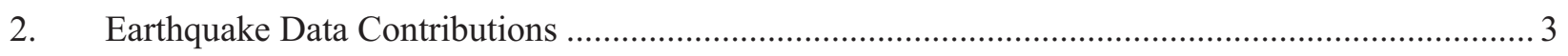

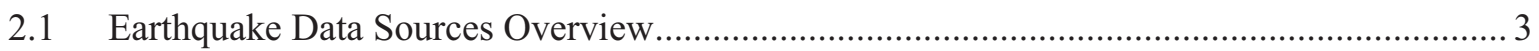

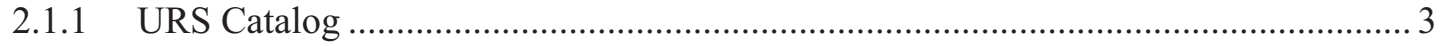

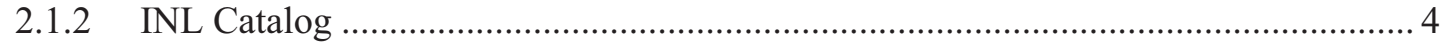

2.1.3 Montana Bureau of Mines and Geology Catalog ........................................................ 4

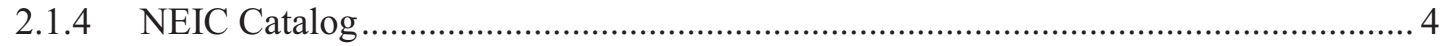



2.1.6 University of Utah Seismograph Stations Catalogs ................................................ 5



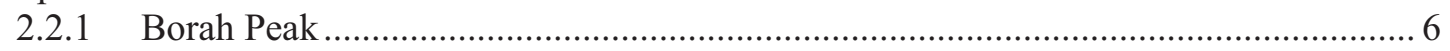

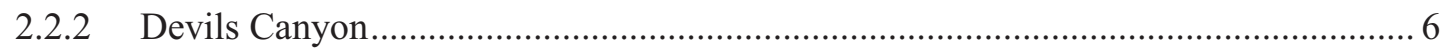

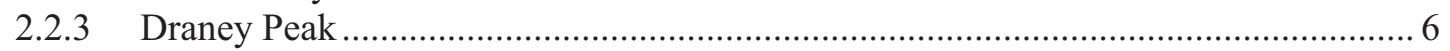

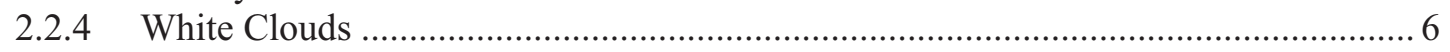

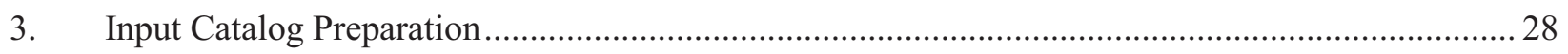

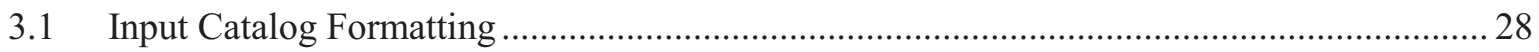



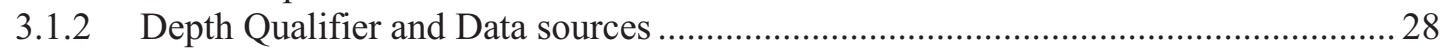

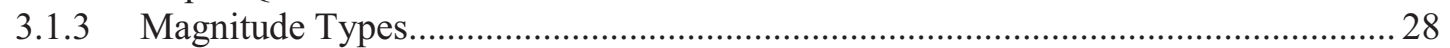

3.1.4 Location Formal Errors ..................................................................................... 28

3.1.5 Location Quality Parameter, Q .................................................................... 29

3.2 Preliminary Searches for Redundant Events within and between Input Catalogs ................ 29

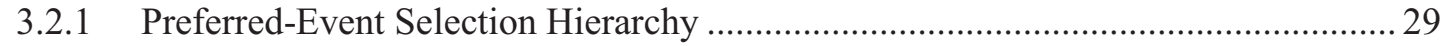

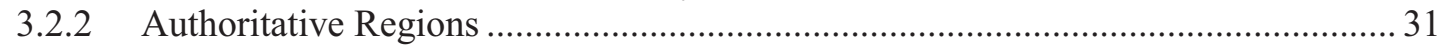

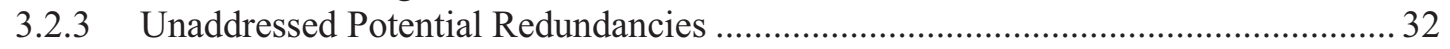

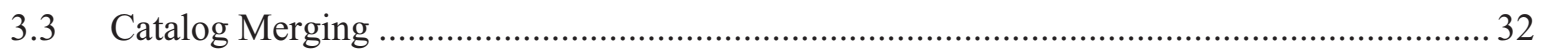

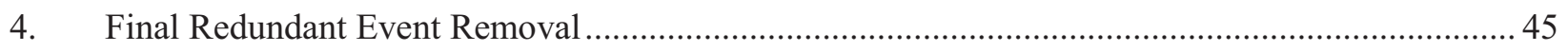

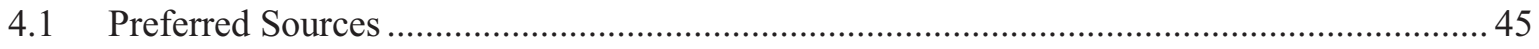

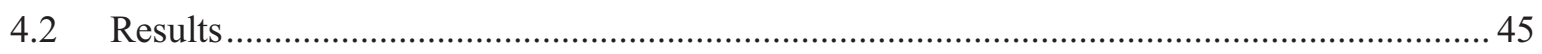

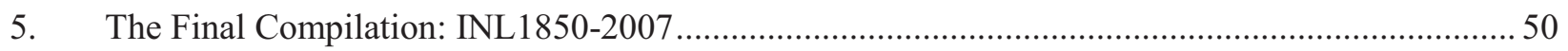

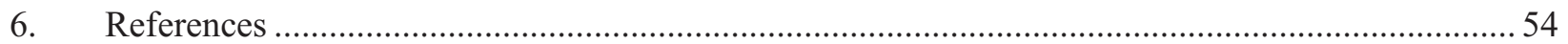




\section{FIGURES}

Figure 2.1 - Map of all events in the URS-ISB1 catalog (1850-1999) used in the creation of the INL1850-2007 compilation along with Quaternary faults within the area of interest (gray line segments), the INL site boundary (black polygon centered in the map), and state borders (labeled with state names). Latitude is in ${ }^{\circ} \mathrm{N}$ and longitude is in ${ }^{\circ} \mathrm{W}$. . 8

Figure 2.2 - Map of all events in the ANSS catalog of magnitude greater than or equal to 2.5 from 1993 through 1999 that were not included in the URS-ISB1 catalog. None of these missing events has a magnitude greater than 3.1. Symbols are as in figure 2.1. 9

Figure 2.3 - Map of all events in the INL2009 catalog (1973-2007) used in the creation of the INL1850-2007 compilation. Symbols are as in figure 2.1.

Figure 2.4 - Map of all events in the MBMG catalog (2000-2007) used in the creation of the INL1850-2007 compilation. Symbols are as in figure 2.1.

Figure 2.5 - Map of all events in the NEIC-PDE catalog (2000-2007) used in the creation of the INL1850-2007 compilation. Symbols are as in figure 2.1.

Figure 2.6 - Map of all events in the PNSN catalog (1995-2007) used in the creation of the INL1850-2007 compilation. Symbols are as in figure 2.1.

Figure 2.7 - Map of all events in the UUSS-UU catalog (2000-2007) used in the creation of the INL1850-2007 compilation. Symbols are as in figure 2.1. 18

Figure 2.8 - Map of all events in the UUSS-WY catalog (2000-2007) used in the creation of the INL1850-2007 compilation. Symbols are as in figure 2.1.

Figure 2.9 - Map of all events in the HUSEN catalog (1972-2007) with suspicious events plotted in blue. Because of the linear trend of these events and frequent suspiciously deep focal depths, these events were considered spurious and removed from the UU-HUSEN catalog. All other events used in the creation of the INL1850-2007 compilation.

Symbols are as in figure 2.1.

Figure 2.10 - Histogram on semi-log axes of the number of events in a given magnitude range that were removed from the UU-HUSEN catalog because they were considered to be biased locations due to the earthquake location procedure. See figure 2.9 for the locations of these events.

Figure 2.11 - Map of all events in the WHITE catalog (1986-2002) used in the creation of the INL1850-2007 compilation. Symbols are as in figure 2.1.

Figure 2.12 - Map of all events in the RICHINS catalog (green) and ZOLL_85 (red) catalog used in the creation of the INL1850-2007 compilation. Symbols are as in figure 2.1.

Figure 2.13 - Map of all events in the ZOLL_94 catalog used in the creation of the INL18502007 compilation. Symbols are as in figure 2.1.

Figure 2.14 - Map of all events in the UU-BRUMB catalog used in the creation of the INL18502007 compilation. Symbols are as in figure 2.1.

Figure 2.15 - Map of all events in the JACKSON catalog used in the creation of the INL18502007 compilation. Symbols are as in figure 2.1.

Figure 3.1 - Flowchart showing the logic used in selecting a preferred event from a list of redundant events for each input catalog. 
Figure 3.2 - Map showing the authoritative regions, colored polygons and line segments, used to select preferred events from a set of duplicate events. If one of the duplicate events is located with the authoritative region and the source of the event's location corresponds to that region, that event is preferred over other redundant events (refer to figure 3.2).

Figure 3.3 - Map showing derived authoritative regions, INL and JLNET, and the stations used to define those regions. The JLNET region was derived considering solely stations in yellow and orange, while the INL region was derived considering all stations, except those in yellow. Other symbols as in figure 2.1.

Figure 3.4 - Map of all events within the file of concatenated catalogs. Symbols as in figure 2.1.......... 44

Figure 4.1 - Flowchart showing the logic used in selecting a preferred event from a list of redundant events for the concatenated file of all input catalogs

Figure 4.2 - Map of all events whose location sources were NEIC and that were selected as the preferred event from a set of redundant events. Also plotted are the authoritative regions as from figure 3.2 for reference. Other symbols are as in figure 2.1.

Figure 5.1 - Map of the INL1850-2007 earthquake compilation used in the SAEP sensitivity analysis. Epicenters are scaled by magnitude. 


\section{TABLES}

Table 2.1. Catalog Input Regions and Sources ..................................................................................... 7

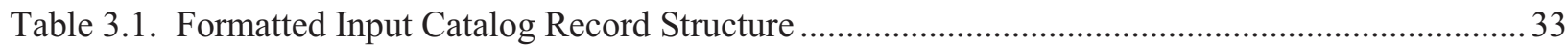



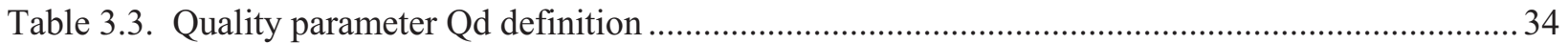

Table 3.4. Other quality codes in URS-ISB1 catalog for events with EQ_src of SRA for years

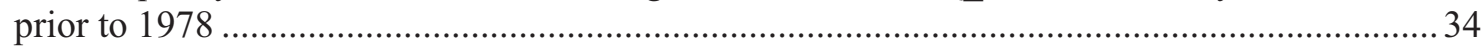

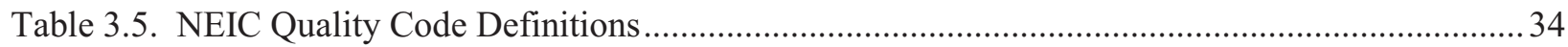

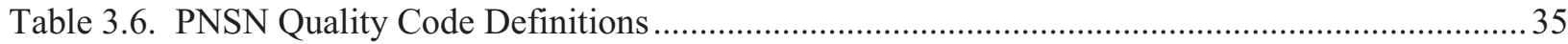



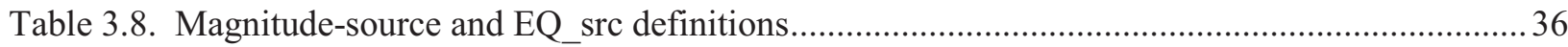



Table 3.10. Examples of Unaddressed, Redundant Events in the URS-ISB1 Catalog .............................39

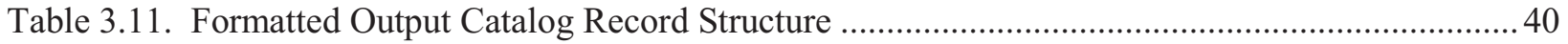

Table 4.1. Comparison of original catalog lengths to number of record contributions in the final

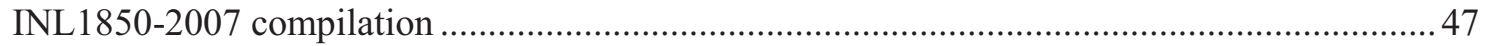

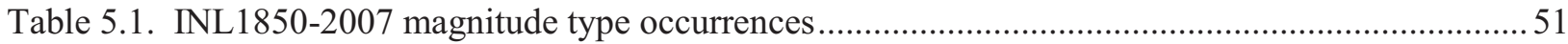




\section{ACRONYMS}

\begin{tabular}{ll} 
DOE & U.S. Department of Energy \\
INL & Idaho National Laboratory \\
SAEP & Seismic Assessment Evaluation Project \\
PSHA & Probabilistic Seismic Hazard Analysis \\
DOE & U.S. Department of Energy \\
ESRP & Eastern Snake River Plain \\
ANSS & Advanced National Seismic System \\
DBE & Design Basis Earthquake \\
MBMG & Montana Bureau of Mines and Geology \\
NEIC & National Earthquake Information Center \\
PNSN & Pacific Northwest Seismic Network \\
USGS & United States Geological Survey \\
UUSS & Surface-Wave Magnitude \\
M & University of Utah Seismograph Stations \\
FA & Intensity Magnitude \\
M $_{\mathrm{d}}$ & Mocal (Richter) Magnitude \\
MI & Felt Area \\
\hline
\end{tabular}




\section{Compilation of Earthquakes from 1850-2007 within 200 miles of the Idaho National Laboratory}

\section{Introduction}

This document describes the creation of an updated earthquake compilation for seismicity within 200 miles of the Idaho National Laboratory (INL); this effort is in support of the Seismic Assessment Evaluation Project (SAEP). The purpose of the SAEP is to conduct an evaluation of the INL Probabilistic Seismic Hazard Analysis (PSHA) in order to meet U.S. Department of Energy (DOE) Order $420.1 \mathrm{~B}$, which states that a review or update of the PSHA should be completed once every 10 years. The evaluation will help determine whether the technical basis of the current design basis earthquake (DBE) levels is defensible or an update is needed for the INL. As part of this effort, the Seismic Evaluation Team (SET) recommended sensitivity analyses. As part of these analyses, they recommended that an updated earthquake catalog be developed and used to calculate recurrence parameters for an alternative zonation model (Schafer and Payne, 2009). This report documents the approach used to develop the 18502007 earthquake compilation for the SAEP.

The 1850-2007 seismicity compilation was developed specifically for use in SAEP sensitivity analyses. It is not recommended for use in an INL PSHA. The 1850-2007 seismicity compilation is an update of the 1850-1992 earthquake compilation used in the 2000 INL PSHA. As such, the earthquake data compiled in this report have not undergone rigorous quality assurance requirements such as qualification of data. This is because results of the sensitivity analyses will only be used as a guide to determining parameter sensitivities and will not used for any seismic safety design calculations. The approach documented in this report provides the starting point for developing an updated earthquake catalog for a future INL PSHA.

\subsection{Background}

The first comprehensive INL PSHA was completed in 1996 which developed uniform hazard spectra (UHS) for rock conditions at all INL facility areas (Woodward-Clyde Federal Services et al. 1996). This PSHA built upon the results and reviews of previous PSHAs conducted at INL in 1990 and 1992 (Woodward-Clyde Consultants 1990; 1992). Further, it incorporated results of all available geologic, seismologic, and geophysical investigations conducted since the 1960's.

The 1996 PSHA provided for explicit inclusion of the range of seismologic and tectonic interpretations for seismic source characterization and ground motion attenuation models. Earthquake magnitudes and recurrence rates were assessed for all earthquake sources including the closest Basin and Range normal faults, dike-induced earthquakes within volcanic rift zones, background (random) earthquakes within the Eastern Snake River Plain (ESRP), and Basin and Range source zones. Ground motion attenuation models included empirical attenuation relationships from other regions and attenuation relationships developed from site-specific stochastic modeling using parameters specific to the ESRP crustal properties. For this effort, the 1850-1992 earthquake catalog was developed for a region encompassing a 200-mile radius of INL (see Appendix A; Woodward-Clyde Federal Services et al. 1996).

In 2000, the PSHA was recomputed for INL facility areas using the same earthquake source characterization models (including the 1850-1992 seismicity catalog) as those in the 1996 evaluation but with updated attenuation relationships. The empirical and stochastic attenuation relationships were applicable to extensional tectonic settings such as the ESRP and Basin and Range (URS Greiner Woodward Clyde Federal Services et al. 1999; 2000). The results of the 2000 PSHA were used to develop 
the Performance Category (PC) 3 and PC 4 DBE ground motion levels that are currently used in seismic analyses at INL facilities.

\subsection{Approach}

To generate the updated INL earthquake compilation, INL1850-2007, earthquake catalogs were collected from several contributing sources. The catalogs were converted to a common format and each catalog was searched for redundant events using the search criteria established for this effort. The catalogs were then concatenated into a single file and time sorted. Finally, the concatenated-catalog file was searched for duplicate entries between contributing catalog sources, employing the same search criteria used for the input catalog redundant-event searches. For all sets of duplicate events, a preferred event was selected, largely based on epicenter-network proximity. All unique magnitude information for each event was added to the preferred event records. This approach yielded the compilation referred to as "INL18502007'. In the following, each of these steps is discussed in detail. 


\section{Earthquake Data Contributions}

The INL1850-2007 compilation is composed of earthquake catalogs from multiple sources. The contributed catalog data, summarized in Table 2.1, originated from three types of sources: historical catalogs, monitoring networks, and special studies. The data gathered from these sources is considered to represent all available earthquake summary data within the $200 \mathrm{mi}(322 \mathrm{~km})$ radius of the INL. This section includes an overview of the contributed earthquake data and brief discussions of each catalog contributed to make the INL1850-2007 compilation. There was no attempt made to compile station lists to assess contributed catalog completeness. However, additional information regarding network operations and procedures for the monitoring networks' and special study's catalogs can be found in the references listed in Table 2.1.

\subsection{Earthquake Data Sources Overview}

A significant catalog in this process was the URS-ISB1 catalog, which is an augmented version of the catalog used for the 1996 INL PSHA (Woodward-Clyde Federal Services et al., 1996) which covered the years from 1850 to 1992. The augmented version expanded upon the catalog used in the 1996 INL PSHA to include earthquakes from 1 January 1993 through 31 December 1999, covering the geographical area of interest ( $322 \mathrm{~km}$ or $200 \mathrm{mi}$ radius of the INL). The greatest import of the URS-ISB1 catalog is in its compilation of historical earthquakes: the source of all earthquakes in the INL1850-2007 compilation with dates on or before 2 November 1972 is the URS-ISB1 catalog.

Other institutions that contributed catalogs included: Montana Bureau of Mines and Geology (MBMG), National Earthquake Information Center (NEIC), Pacific Northwest Seismic Network (PNSN), and the University of Utah Seismograph Stations (UUSS) Yellowstone (UUSS-WY) and Utah networks (UUSS-UU). The University of Nevada at Reno catalog was not included in this process as its seismicity catalog has been submitted to the NEIC ${ }^{1}$. A request was made to each of these institutions for electronic copies of their earthquake data to add events beyond the last date of the URS-ISB1 catalog. Requests were made for earthquakes between 1 January 2000 and 31 December 2007, and within the following geographical ranges: $40.5^{\circ}-47.0^{\circ} \mathrm{N}$ and $109.0^{\circ}-117.0^{\circ} \mathrm{W}$. Additionally, the entire INL catalog, from 1973 -2007 , within the same area was also used. Finally, several special-study catalogs were incorporated (see Table 2.1).

\subsubsection{URS Catalog}

The catalog contributed by URS is called the ISB1 catalog, herein URS-ISB1 (F. Terra, pers. comm., 2009b). This catalog includes the catalog used for the 1996 PSHA (Woodward-Clyde Federal Services et al., 1996) and also data compiled by URS for the years 1993 through 1999 contributed by MBMG, NEIC, U.S. Bureau of Reclamation (Jackson Lake Network), and UUSS, (F. Terra, pers. comm., 2009a). Figure 2.1 is a plot of all 26,341 events in the URS-ISB1 catalog used in the creation of the INL1850-2007 catalog.

\footnotetext{
${ }^{1}$ Biasi, G., 2009, University of Nevada at Reno, Nevada Seismological Laboratory, Personal communication with N.S.
} Carpenter. 
Aside from events that are known to be absent from URS-ISB1 (INL2009, JACKSON, RICHINS , UU-BRUMB, UU-HUSEN, UU-WHITE, ZOLL_85, and ZOLL_94; see below), it is assumed that this catalog contains all located events of significance within this region, prior to 2000 . To evaluate its contents, the URS-ISB1 was searched for all events in the ANSS catalog (ANSS, 2009a) of magnitude 2.5 and greater that occurred from 1993 through 1999 - the dates of data in the URS-ISB1 catalog not included in the 1996 PSHA - in the same geographic area. The ANSS catalog is appropriate for comparison because all networks surrounding the INL (PNSN, UUSS, and MBMG) and the NEIC contribute their earthquake catalogs to ANSS.

With the exception of 24 events of magnitude less than 3.2 (see figure 2.2), all of the 1,026 events in the ANSS catalog were found in the URS-ISB1 catalog. Therefore, it was concluded that the URS-ISB1 catalog could be considered to contain the significant, located events through 1999 with all known historic seismicity, except for the catalogs that are known to be absent (discussed below).

\subsubsection{INL Catalog}

The catalog contributed by the INL, herein INL2009, was created by the INL Seismic Monitoring Program (Payne et al., 2008) whose network started with one seismic station in 1971 and increased to the currently operating 27 stations in 1994 (figure 2.3). The INL2009 catalog covered the time period from 16 May, 1973 through 31 December, 2007. All 14,854 events from the INL2009 catalog within that date range that fell within the region of interest were used (many prior to 2000 were not included in the original ISB1 catalog) and they are plotted in the figure 2.4.

\subsubsection{Montana Bureau of Mines and Geology Catalog}

The catalog contributed by MBMG, herein MBMG, was created by the Montana Bureau of Mines and Geology (Stickney, 2006) which monitors the area from $44.0^{\circ} \mathrm{N}$ to $50.0^{\circ} \mathrm{N}$ and $103.0^{\circ} \mathrm{W}$ to $117.0^{\circ} \mathrm{W}$ and routinely locates seismicity within the area of interest. MBMG operated from 29 to 36 seismic stations and monitored at least 50 additional stations from nearby networks from 2000 through 2007 (figure 2.5). The 11,776 contributed events within the region of interest are plotted the figure 2.6.

\subsubsection{NEIC Catalog}

The USGS PDE (Preliminary Determination of Epicenters) catalog, herein NEIC-PDE, maintained by the NEIC (NEIC, 2009) was used. The NEIC monitors the U.S. and global seismicity and has operated at least 10 seismic stations within the local area from 2000 through 2007. The 209 events in the subset of the NEIC PDE catalog used are plotted in figure 2.7.

\subsubsection{Pacific Northwest Seismic Network Catalog}

The PNSN catalog, herein PNSN, was created by the Pacific Northwest Seismic Network (PNSN, 2009). While seismicity in the area around the INL is outside of the PNSN monitoring network (figure 2.8), the PNSN occasionally locates seismicity within the area of interest. All 302 contributed events used are plotted in figure 2.9. It is noted that for the PNSN catalog, events from 1995 through 2007 and from $\mathrm{N} 40^{\circ}$ through $47^{\circ}$ were used. 


\subsubsection{University of Utah Seismograph Stations Catalogs}

The UUSS, which routinely locates seismicity within the region of interest, contributed several catalogs which are briefly discussed below.

\subsubsection{UU catalog}

The UU catalog (UUSS-UU, 2009) produced by UUSS, herein UUSS-UU, covers the Utah region and a small region in southeastern Idaho from $\mathrm{N} 36.75^{\circ}-42.50^{\circ}$ and $\mathrm{W} 108.75^{\circ}-114.25^{\circ}$ and was monitored by 72 UUSS stations in 1996, increasing to 175 UUSS stations in 2006 (figure 2.10). The 2,780 UU events within the local are of interest and used to build the INL1850-2007 compilation are plotted in figure 2.11 .

\subsubsection{WY catalog}

The WY catalog (UUSS-WY, 2009), herein UUSS-WY, produced by UUSS covers the Yellowstone National Park region from N 44.00 $-45.17^{\circ}$ and $\mathrm{W} 109.75^{\circ}-111.50^{\circ}$ and was monitored by at least 19 UUSS stations in 1995, increasing to 26 UUSS stations in 2006. The 11,855 WY events are plotted in figure 2.8.

\subsubsection{Relocated Yellowstone Catalog}

A subset of the UUSS WY catalog was relocated with a more accurate, three-dimensional velocity model and a non-linear earthquake location algorithm by Husen and Smith (2004). Except for the events discussed below, this entire relocated catalog, from 1972 through 2007, was used because the event locations therein should be more accurate than those found in the URS and UUSS-WY catalogs.

Within this catalog, there were many events which seemed to be artifacts of a location procedure. These epicenters trended linearly, delineating a geographic boundary and the focal depths were often anomalously deep (almost 100 events had depths greater than or equal to $30 \mathrm{~km}$ ). The linear trend and frequent anomalous depths likely indicate ill-constrained hypocenters whose locations were mathematically restrained to fall within a pre-defined area, and which should not be included in an earthquake catalog; these events were removed from the UU-HUSEN catalog. Figure 2.14 shows the UU-HUSEN catalog and the removed events. Figure 2.15 shows a histogram of the number of events of given magnitude that were removed by this procedure. Of those, only 10 events of magnitude 2.5 and greater were not redundant - i.e., only 10 of those events are absent in the INL1850-2007 compilation. Those 10 events spanned the years 1974 to 1991 and had magnitudes from $M_{d} 2.5$ to $M_{d}$ 3.6.

\subsubsection{Relocated Teton Catalog}

Earthquake data from the Jackson Lake Seismic Network, which consisted of 16 to 25 stations operating from 1986 into 2002 (figure 3.3), were used to locate events with a three-dimensional velocity model and a non-linear earthquake location algorithm by White et al. (2009). This catalog of 8,505 events, herein UU-WHITE, is plotted in figure 2.16. 


\subsection{Special Studies}

Several special studies were carried out within the region of interest which most commonly involved local, temporary network monitoring of aftershocks following a large main shock. Catalogs from these studies are discussed below.

\subsubsection{Borah Peak}

Events related to the $1983 \mathrm{M}_{\mathrm{s}}$ 7.3 Borah Peak earthquake were contributed from two special studies, discussed below. The events in these catalogs are plotted in figure 2.17.

Richins et al., 1985; 1987

Within hours following the 28 October 1983 Borah Peak earthquake, a dense network of up to 45 seismographs was installed in the region around the epicenter. This temporary network operated for 22 days and the catalog of 421 events which resulted (Richins et al. 1985; 1987), herein RICHINS, was incorporated into the INL1850-2007 catalog.

Zollweg and Richins, 1985

After the temporary network was removed, aftershocks following the 1983 Borah Peak earthquake were monitored and located using regional seismic stations, supplemented by sporadic local monitoring, by Zollweg and Richins (1985). The resultant catalog, herein ZOLL_85, consisted of 111 events.

\subsubsection{Devils Canyon}

Almost a year after the 1983 Borah Peak earthquake, the 1984 Devil Canyon sequence initiated with a $\mathrm{M}_{\mathrm{L}} 5.8$ earthquake at the projected intersection of two normal faults: the Challis segment of the Lost River fault and the Lone Pine fault (Payne et al., 2004). Three hundred and fourteen (314) events from this sequence, herein ZOLL_94, were located by a dense network of up to 22 stations and are plotted in figure 2.18 .

\subsubsection{Draney Peak}

Following the $\mathrm{M}_{\mathrm{w}}$ 5.7 Draney Peak, Idaho, earthquake on February 3, 1994, a temporary network of 10 seismographs was deployed in the region around the epicenter (Brumbaugh, 2001). A catalog of 480 aftershocks, herein UU-BRUM, located during this study are plotted in figure 2.19.

\subsubsection{White Clouds}

A sequence of more than 1800 earthquakes occurred in September 1986, roughly $50 \mathrm{~km}$ west of the 1983 Borah Peak earthquake. The largest event in this sequence was a $\mathrm{M}_{\mathrm{L}} 4.5$ (Jackson and Zollweg, 1988). A temporary network of 16 seismographs was installed to monitor the seismicity and of those events detected by the network, 191 composed the catalog herein called JACKSON and are plotted in figure 2.20 . 
Table 2.1. Catalog input regions and data sources

\begin{tabular}{|c|c|c|c|c|}
\hline Catalog Name & $\begin{array}{l}\text { Region Covered: } \\
\text { Latitude; Longitude Range }\end{array}$ & Date Range & Data Source & References \\
\hline URS-ISB1 & $\begin{array}{l}\text { Entire Region: } \\
40.5^{\circ}-47^{\circ} \mathrm{N} ; 117^{\circ}-109^{\circ} \mathrm{W}\end{array}$ & $1850-1999$ & URS & $\begin{array}{l}\text { Woodward-Clyde Federal Services et } \\
\text { al., 1996; F. Terra, pers. comm., } 2009 b\end{array}$ \\
\hline HUSEN & $\begin{array}{l}\text { Yellowstone Nat'l Park Region } \\
43.5^{\circ}-45.4^{\circ} \mathrm{N} ; 112^{\circ}-109.7^{\circ} \mathrm{W}\end{array}$ & $1972-2007$ & University of Utah & Husen and Smith, 2004; Farrell, 2009 \\
\hline INL2009 & $\begin{array}{l}\text { Entire Region: } \\
40.7^{\circ}-46.8^{\circ} \mathrm{N} ; 116.5^{\circ}-109^{\circ} \mathrm{W}\end{array}$ & 1973-2007 & INL & Payne et al., 2008 \\
\hline RICHINS & $\begin{array}{l}\text { Borah Peak Aftershock Region: } \\
43.8^{\circ}-45^{\circ} \mathrm{N} ; 114.6^{\circ}-113.6^{\circ} \mathrm{W}\end{array}$ & $\begin{array}{l}1983 / 10 / 28- \\
1983 / 11 / 19\end{array}$ & University of Utah & Richins et al., 1985; 1987 \\
\hline ZOLL_85 & $\begin{array}{l}\text { Borah Peak Aftershock Region: } \\
44^{\circ}-44.7^{\circ} \mathrm{N} ; 114.9^{\circ}-113.8^{\circ} \mathrm{W}\end{array}$ & $\begin{array}{l}1983 / 11 / 21- \\
1984 / 8 / 21\end{array}$ & $\begin{array}{l}\text { University of } \\
\text { Washington }\end{array}$ & Zollweg and Richins, 1985 \\
\hline ZOLL_94 & $\begin{array}{l}\text { Devil Canyon Aftershock Region: } \\
44.3^{\circ}-44.7^{\circ} \mathrm{N} ; 114.6^{\circ}-114^{\circ} \mathrm{W}\end{array}$ & $\begin{array}{l}1984 / 8 / 27- \\
1994 / 6 / 15\end{array}$ & $\begin{array}{l}\text { Boise State } \\
\text { University }\end{array}$ & $\begin{array}{l}\text { Payne et al., 2004; J. Zollweg, pers. } \\
\text { comm., } 1994\end{array}$ \\
\hline WHITE & $\begin{array}{l}\text { Teton Nat'l Park Region } \\
43^{\circ}-44.5^{\circ} \mathrm{N} ; 111.6^{\circ}-109.5^{\circ} \mathrm{W}\end{array}$ & $1986-2002$ & University of Utah & White et al., 2009; J. Farrell, 2009 \\
\hline JACKSON & $\begin{array}{l}\text { White Clouds Sequence: } \\
43.9^{\circ}-44.2^{\circ} \mathrm{N} ; 114.7^{\circ}-114^{\circ} \mathrm{W}\end{array}$ & $\begin{array}{l}1986 / 10 / 05- \\
1986 / 10 / 25\end{array}$ & INL & Jackson and Zollweg, 1988 \\
\hline UU-BRUM & $\begin{array}{l}\text { Draney Peak Sequence: } \\
42.5^{\circ}-42.9^{\circ} \mathrm{N} ; 111.5^{\circ}-111^{\circ} \mathrm{W}\end{array}$ & $\begin{array}{l}1994 / 1 / 03- \\
1994 / 9 / 30\end{array}$ & University of Utah & Brumbaugh, 2001 \\
\hline PNSN & $\begin{array}{l}\text { Entire Region: } \\
40.2^{\circ}-47^{\circ} \mathrm{N} ; 117^{\circ}-109^{\circ} \mathrm{W}\end{array}$ & $1995-2007$ & PNSN & Wright, 2008; PNSN, 2009 \\
\hline MBMG & $\begin{array}{l}\text { Entire Region: } \\
41.1^{\circ}-47^{\circ} \mathrm{N} ; 117^{\circ}-109^{\circ} \mathrm{W}\end{array}$ & $2000-2007$ & MBMG & Stickney, 2006; Stickney, 2009 \\
\hline NEIC & $\begin{array}{l}\text { Entire Region: } \\
40.5^{\circ}-47^{\circ} \mathrm{N} ; 117^{\circ}-109^{\circ} \mathrm{W}\end{array}$ & $2000-2007$ & NEIC-PDE & NEIC, 2009 \\
\hline UUSS-UU & $\begin{array}{l}\text { Utah and SE Idaho: } \\
40.5^{\circ}-42.5^{\circ} \mathrm{N} ; 114.2^{\circ}-109^{\circ} \mathrm{W}\end{array}$ & $2000-2007$ & UUSS & Pechmann, 2009; UUSS-UU, 2009 \\
\hline UUSS-WY & $\begin{array}{l}\text { Yellowstone Nat'1 Park Region } \\
44^{\circ}-45.2^{\circ} \mathrm{N} ; 111.5^{\circ}-109.75^{\circ} \mathrm{W}\end{array}$ & $2000-2007$ & UUSS & Pechmann, 2009; UUSS-WY, 2009 \\
\hline
\end{tabular}




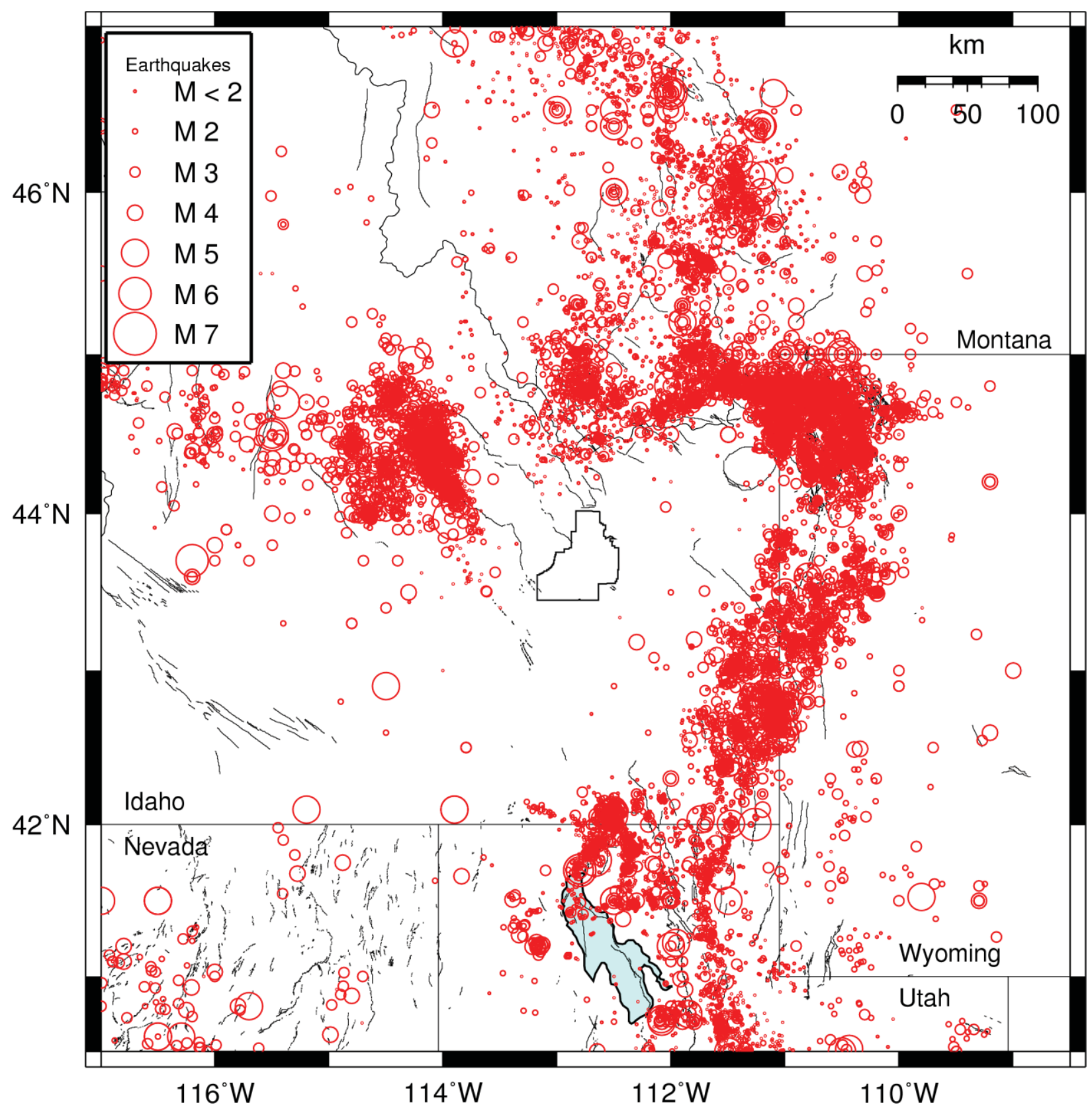

Figure 2.1 - Map of all events in the URS-ISB1 catalog (1850-1999) used in the creation of the INL18502007 compilation along with Quaternary faults within the area of interest (gray line segments), the INL site boundary (black polygon centered in the map), and state borders (labeled with state names). 




Figure 2.2 - Map of all events in the ANSS catalog of magnitude greater than or equal to 2.5 from 1993 through 1999 that were not included in the URS-ISB1 catalog. None of these missing events has a magnitude greater than 3.1. Symbols are as in figure 2.1. 


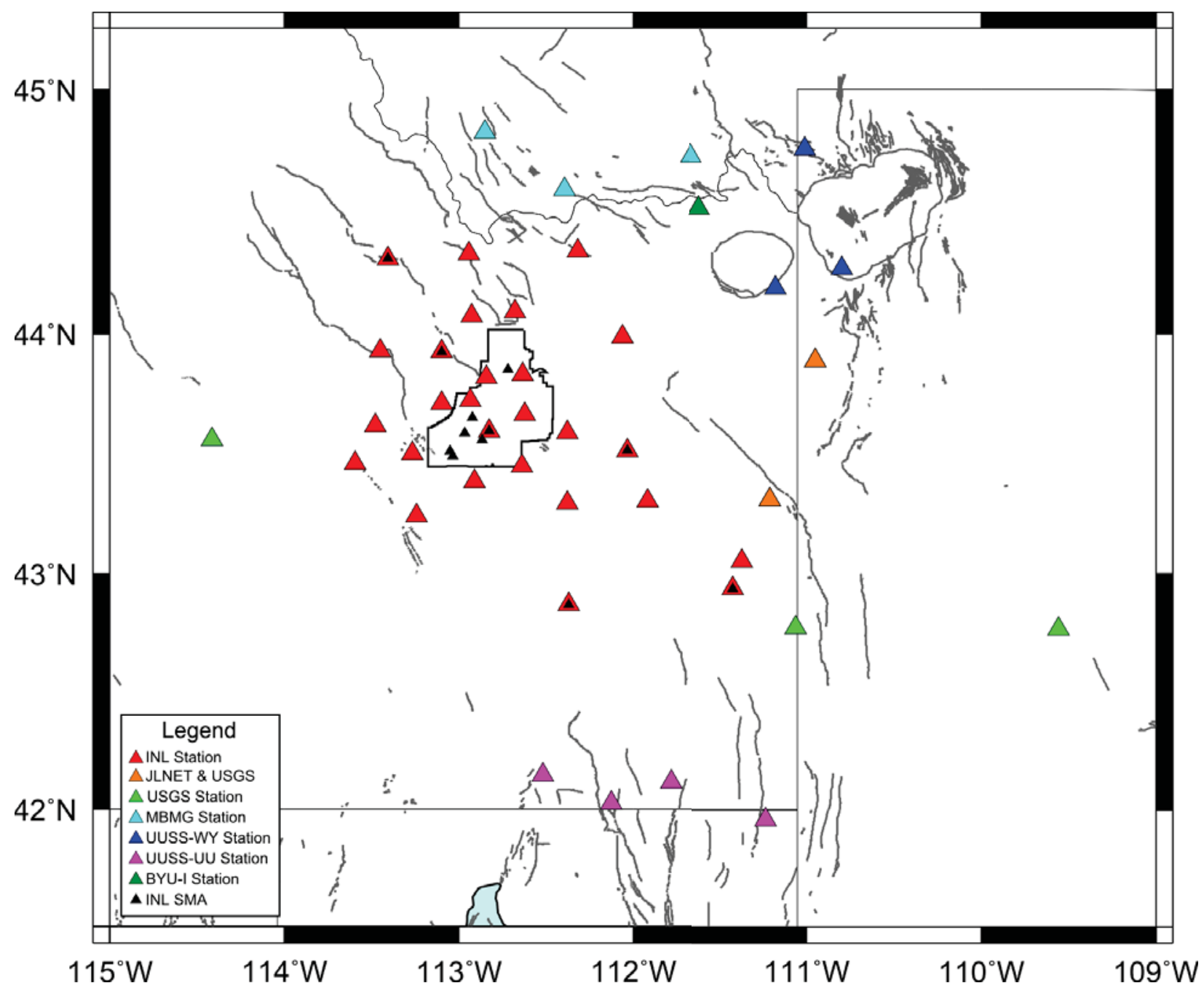

Figure 2.3 - Map of all stations monitored by the INL through 2007. Stations are colored by the operating network. 


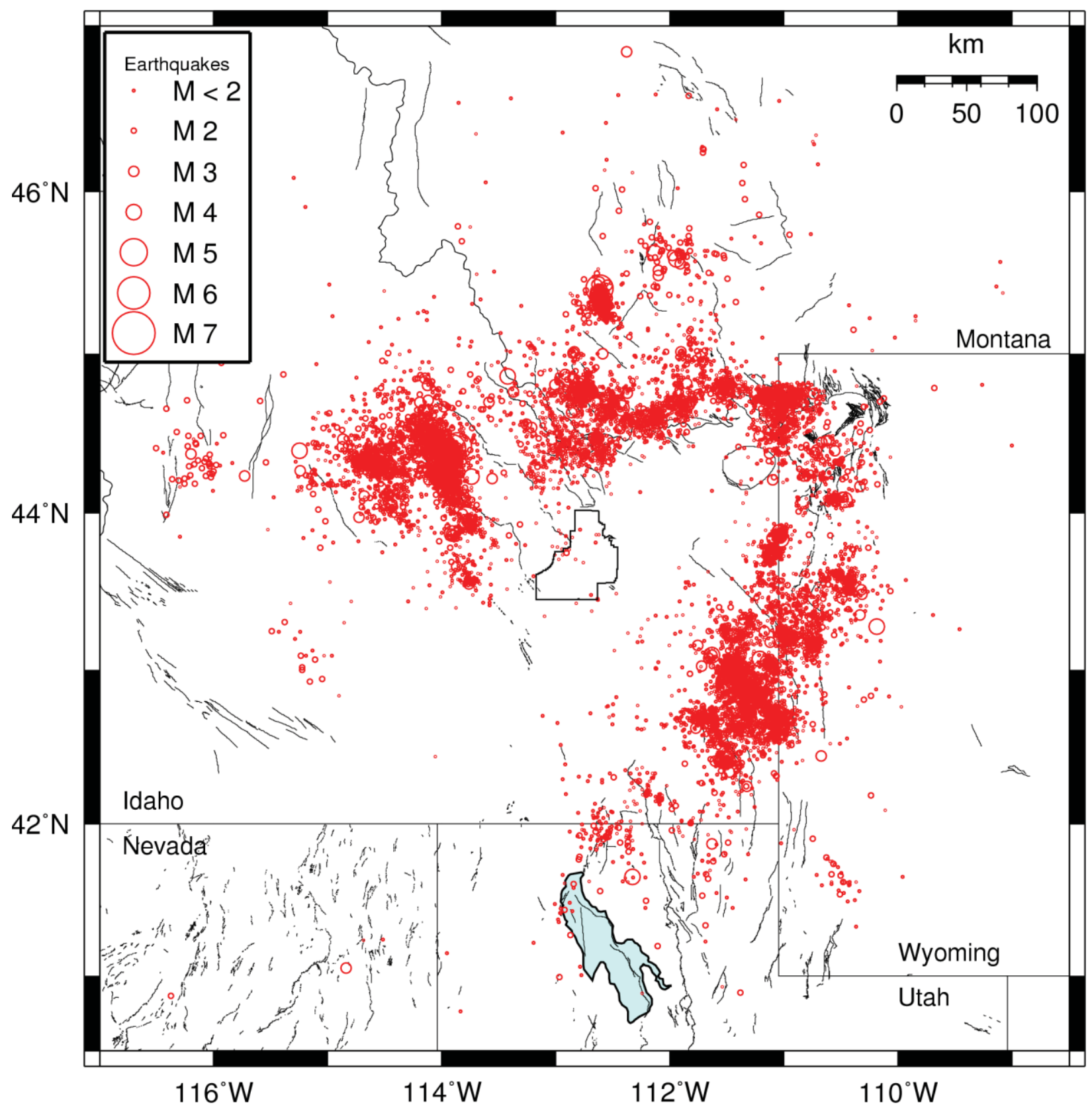

Figure 2.4 - Map of all events in the INL2009 catalog (1973-2007) used in the creation of the INL18502007 compilation. Symbols are as in figure 2.1. 




Figure 2.5 - Map of all stations monitored by MBMG through 2007. Stations are colored by the operating network coded as follows: MB - MBMG, UI - University of Idaho, US - USGS, IU - Global Seismic Network, CN - Canadian National Seismograph Network, UW - PNSN, IE - INL, WY - UUSSWY, RC, Brigham Young University - Idaho, and TA -USArray Transportable Array network (EarthScope, 2010). 


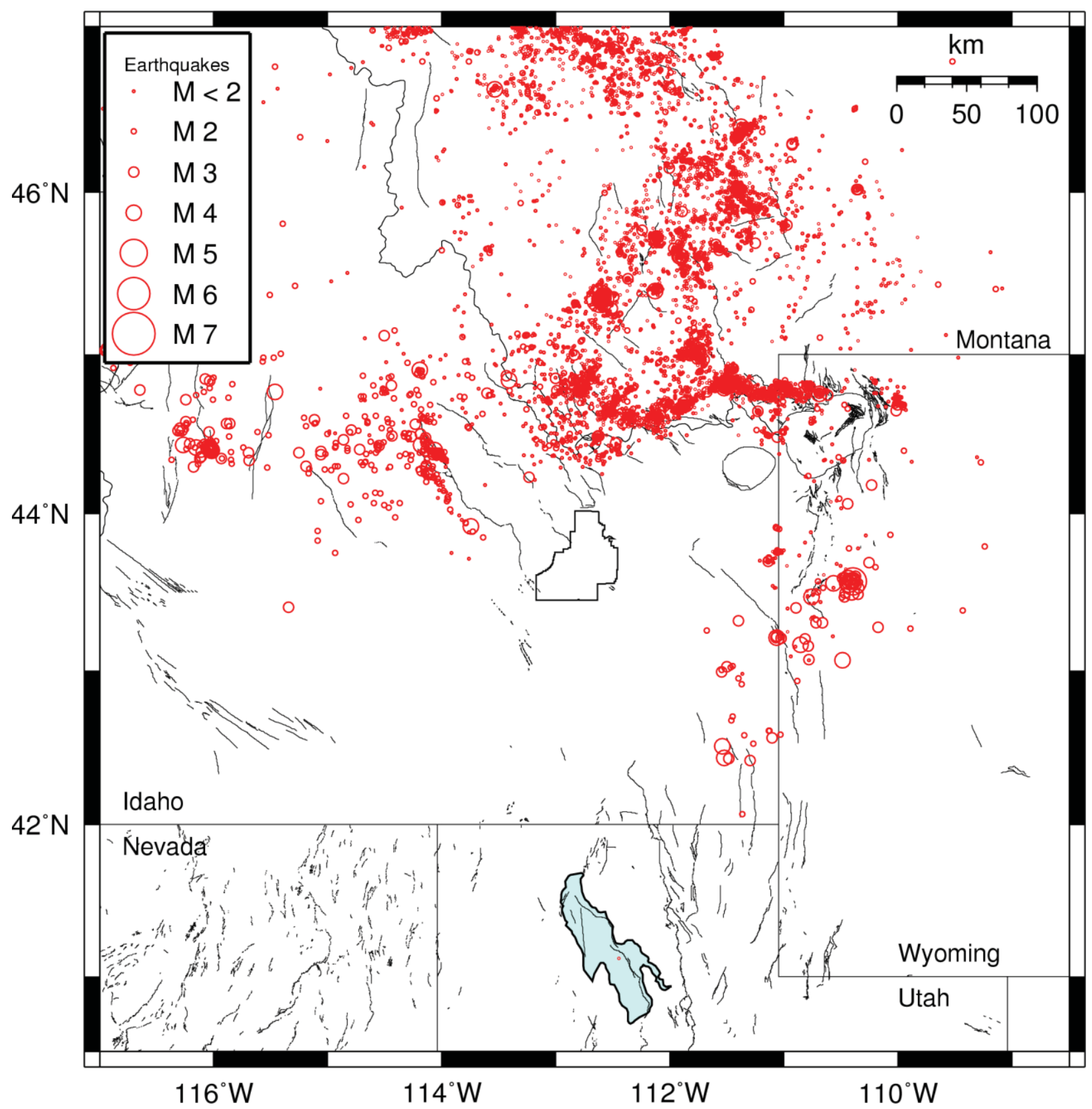

Figure 2.6 - Map of all events in the MBMG catalog (2000-2007) used in the creation of the INL18502007 compilation. Symbols are as in figure 2.1. 


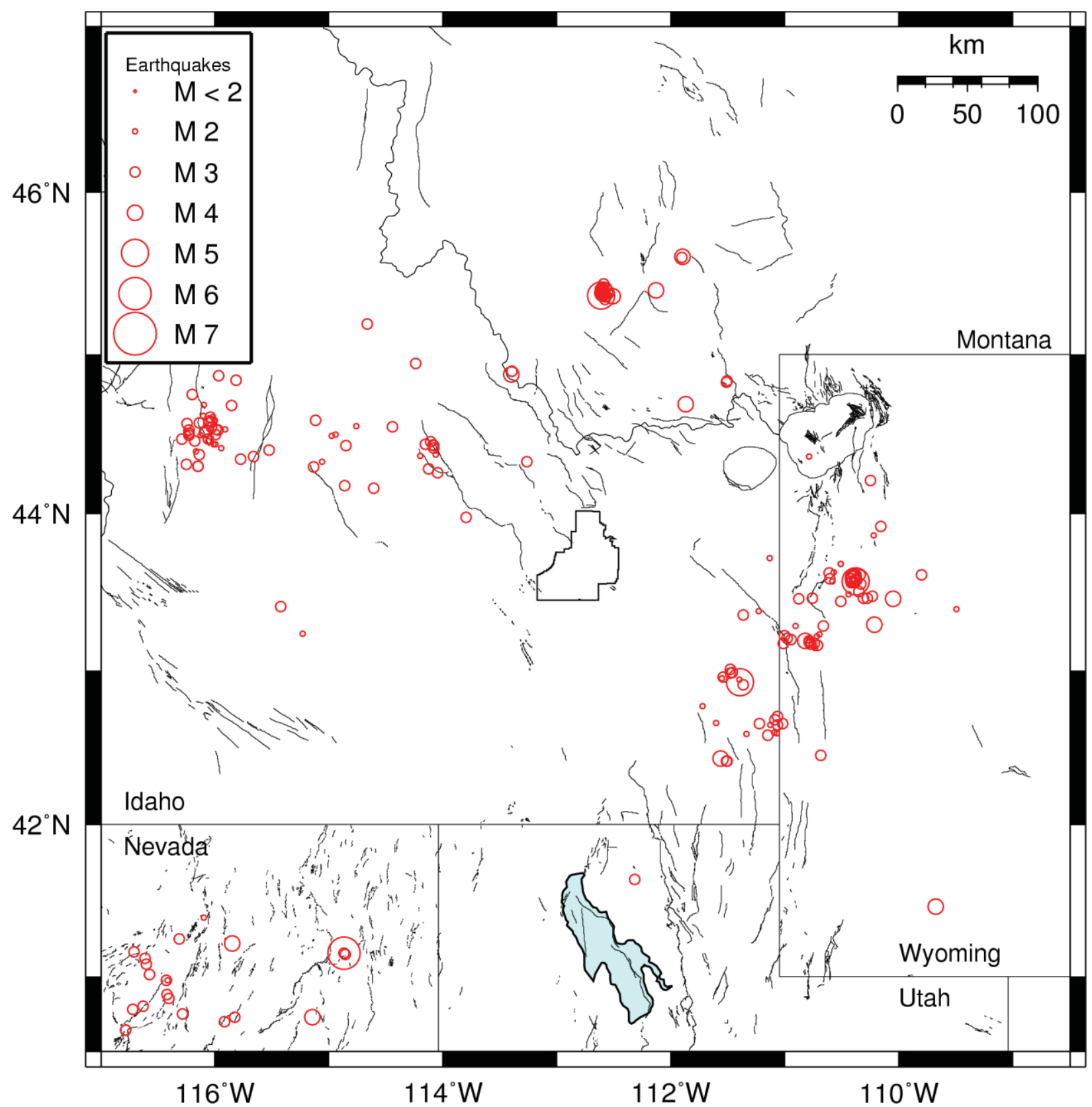

Figure 2.7 - Map of all events in the NEIC-PDE catalog (2000-2007) used in the creation of the INL1850-2007 compilation. Symbols are as in figure 2.1. 




Figure 2.8 - Map of most stations monitored by PNSN through 2007 (other stations are north and south of the map plot area). Stations are colored by the operating network coded as follows: UW - PNSN, MB MBMG, US - USGS, CN - Canadian National Seismograph Network, TA -USArray Transportable Array network, NP - US National Strong-Motion Network, NC - Northern California, CC - Cascade Chain Volcano Monitoring, HW - Hanford Washington Seismic Network, UO - University of Oregon Regional Network, BK - Berkeley Digital Seismograph Network, IE - INL, and NA - Unaffiliated station in the PNSN seismic station list. 


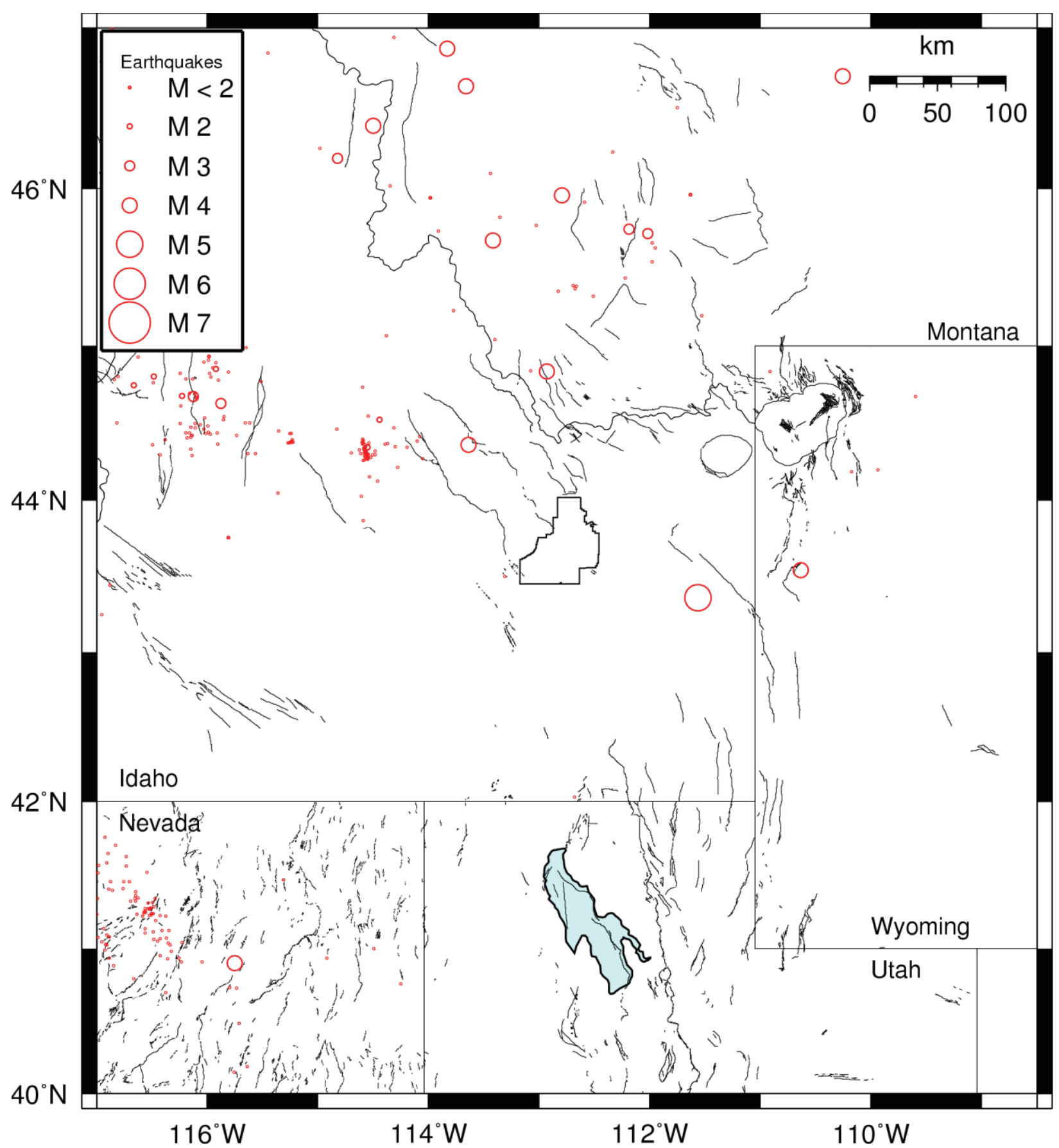

Figure 2.9 - Map of all events in the PNSN catalog (1995-2007) used in the creation of the INL18502007 compilation. Symbols are as in figure 2.1. 


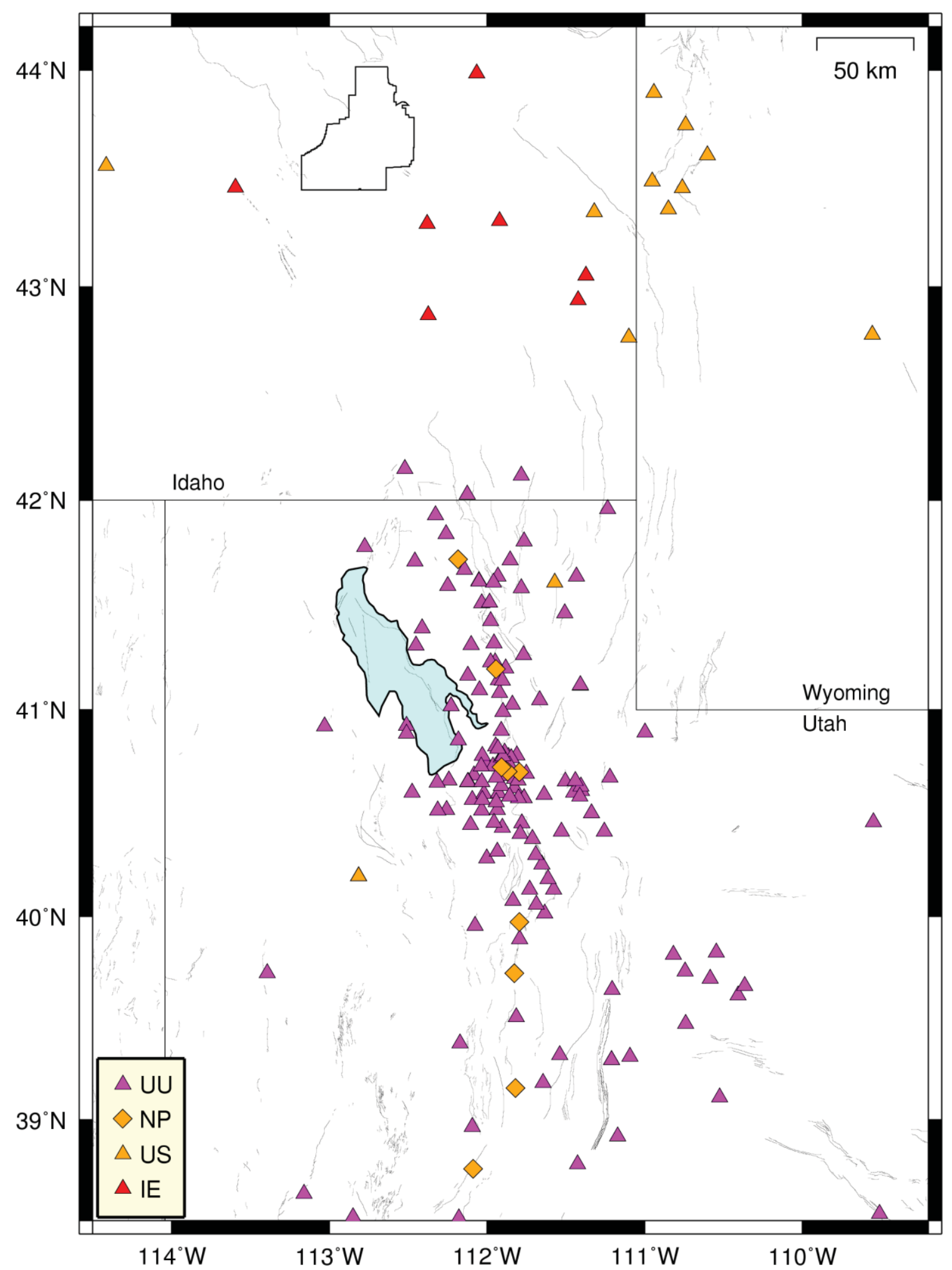

Figure 2.10 - Map of stations monitored by UUSS-UU through 2007 (other stations are north and south of the map plot area). Stations are colored by the operating network coded as follows: UU - UUSS-UU, NP - US National Strong-Motion Network, US - USGS, and IE - INL. 


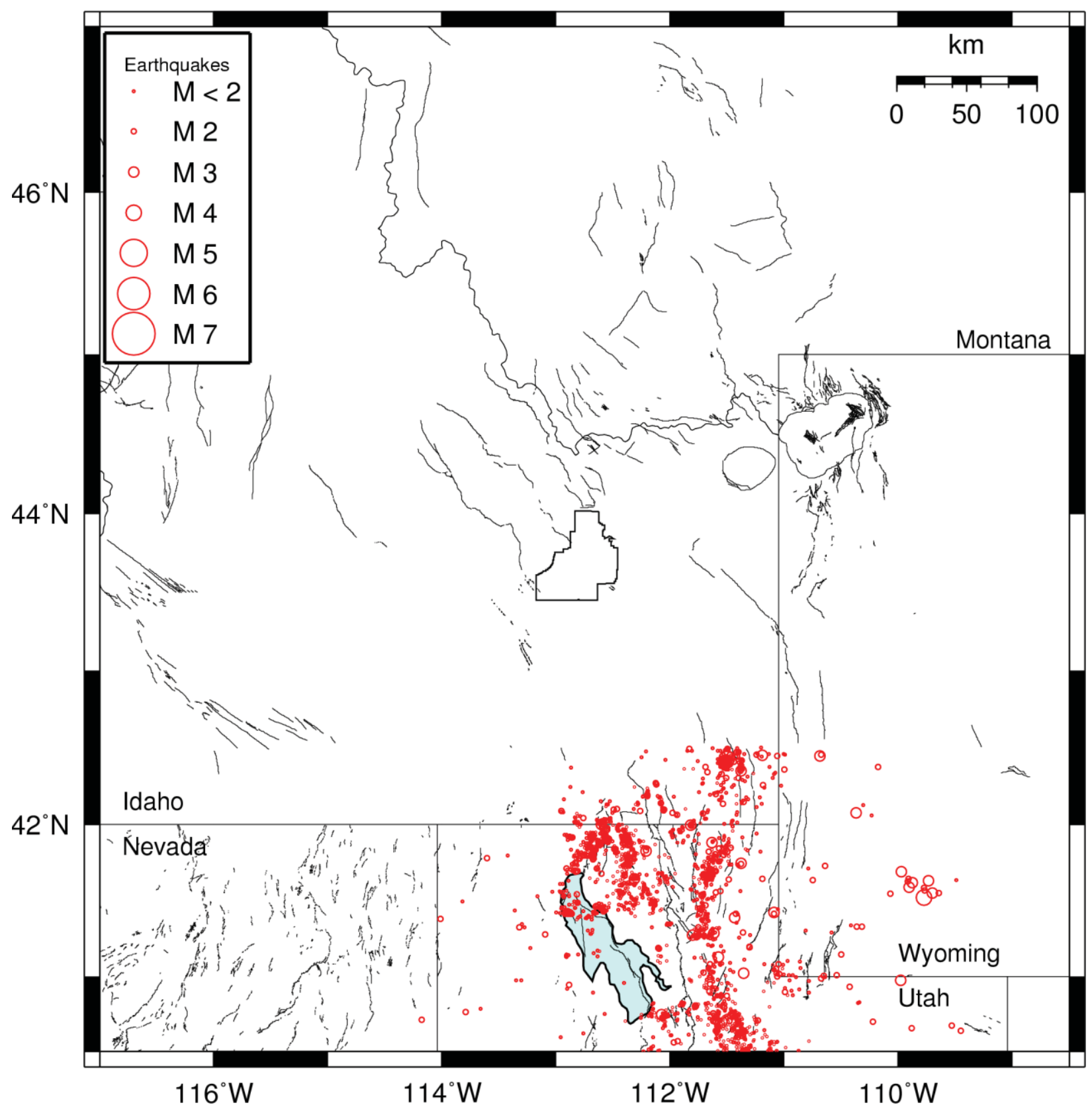

Figure 2.11 - Map of all events in the UUSS-UU catalog (2000-2007) used in the creation of the INL1850-2007 compilation. Symbols are as in figure 2.1. 


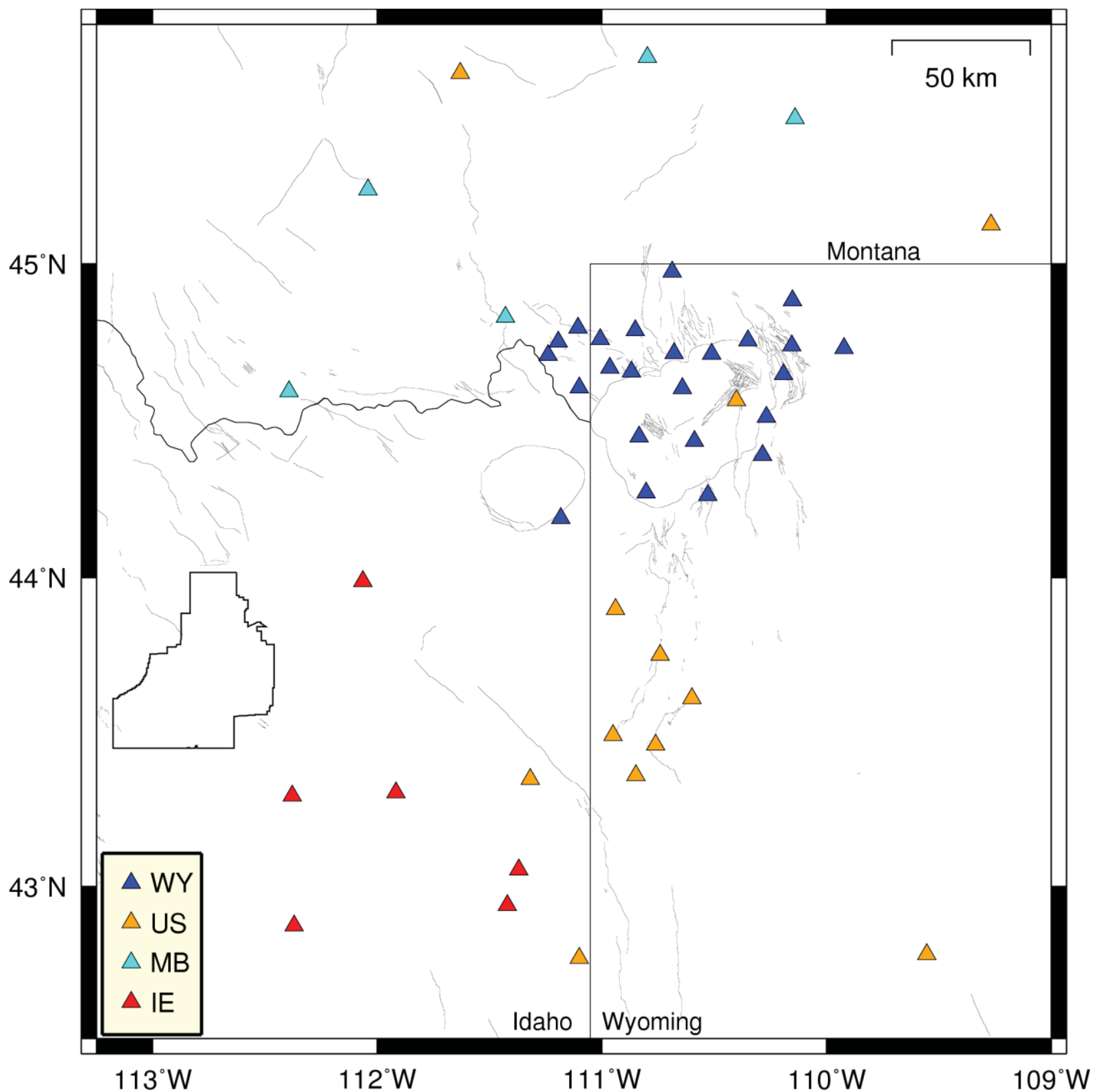

Figure 2.12 - Map of stations monitored by UUSS-WY through 2007. Stations are colored by the operating network coded as follows: WY - UUSS-WY, US - USGS, MB - MBMG, and IE - INL. 


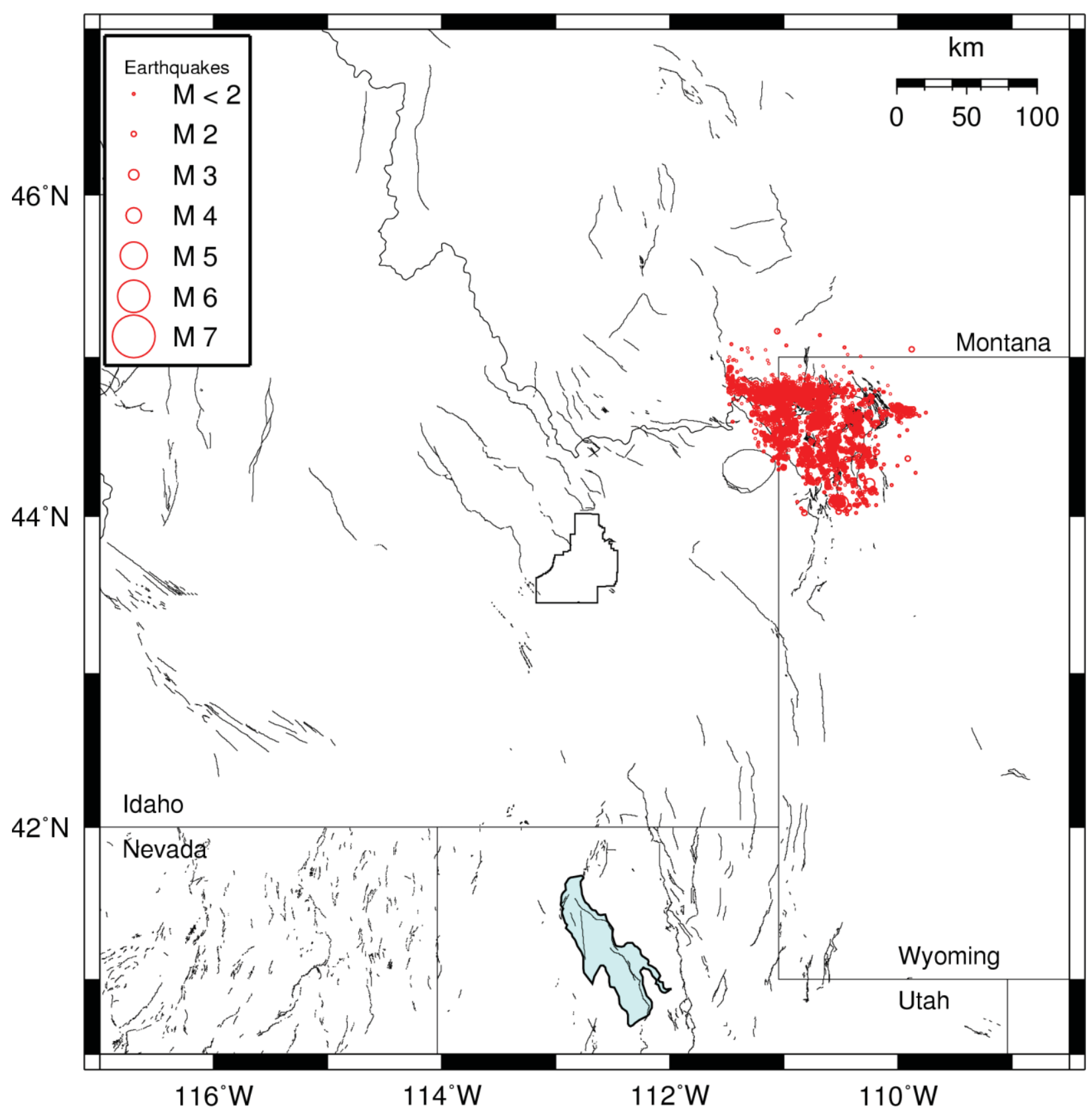

Figure 2.13 - Map of all events in the UUSS-WY catalog (2000-2007) used in the creation of the INL1850-2007 compilation. Symbols are as in figure 2.1. 


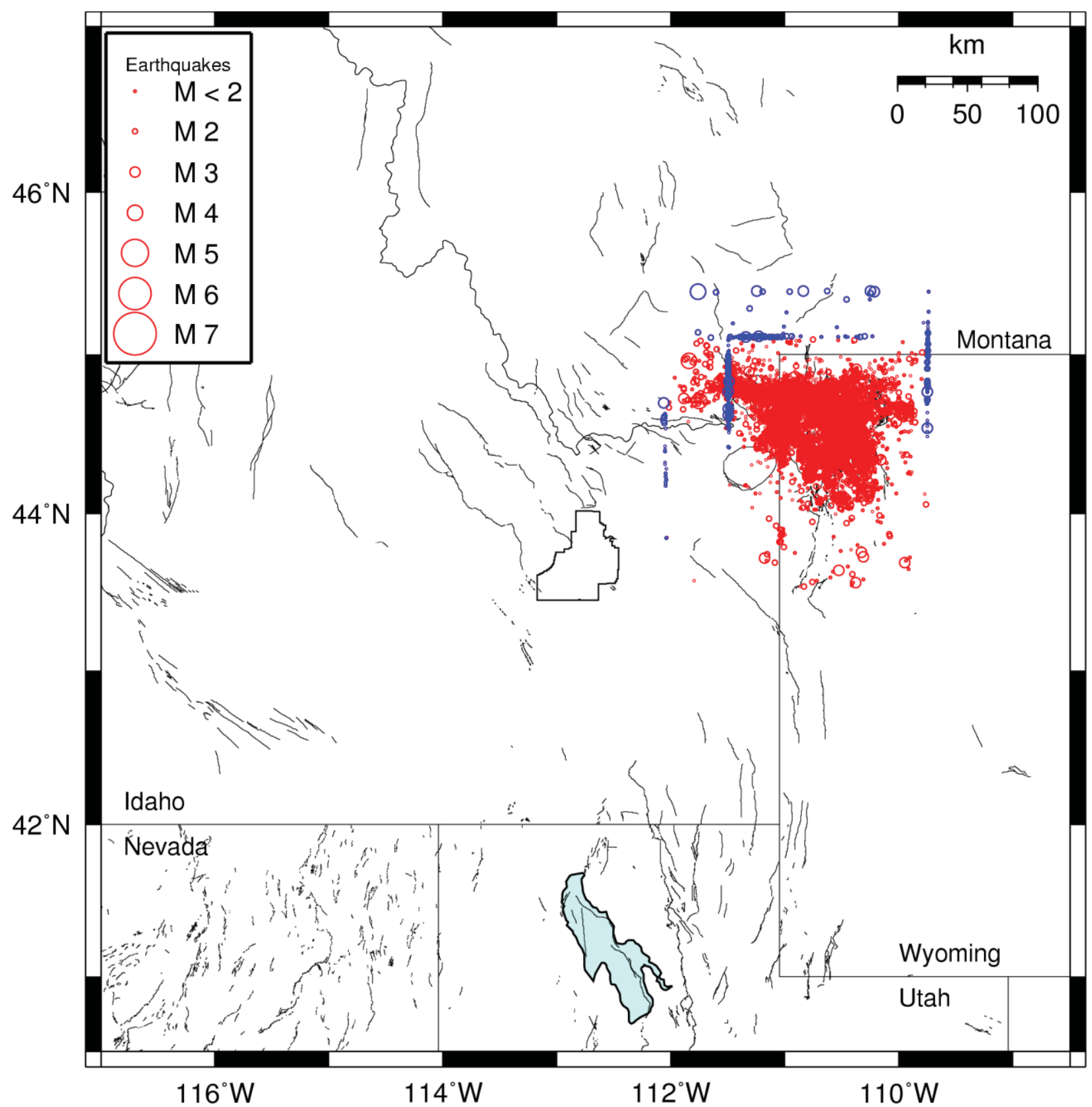

Figure 2.14 - Map of all events in the HUSEN catalog (1972-2007) with suspicious events plotted in blue. Because of the linear trend of these events and frequent suspiciously deep focal depths, these events were considered spurious and removed from the UU-HUSEN catalog. All other events used in the creation of the INL1850-2007 compilation. Symbols are as in figure 2.1. 


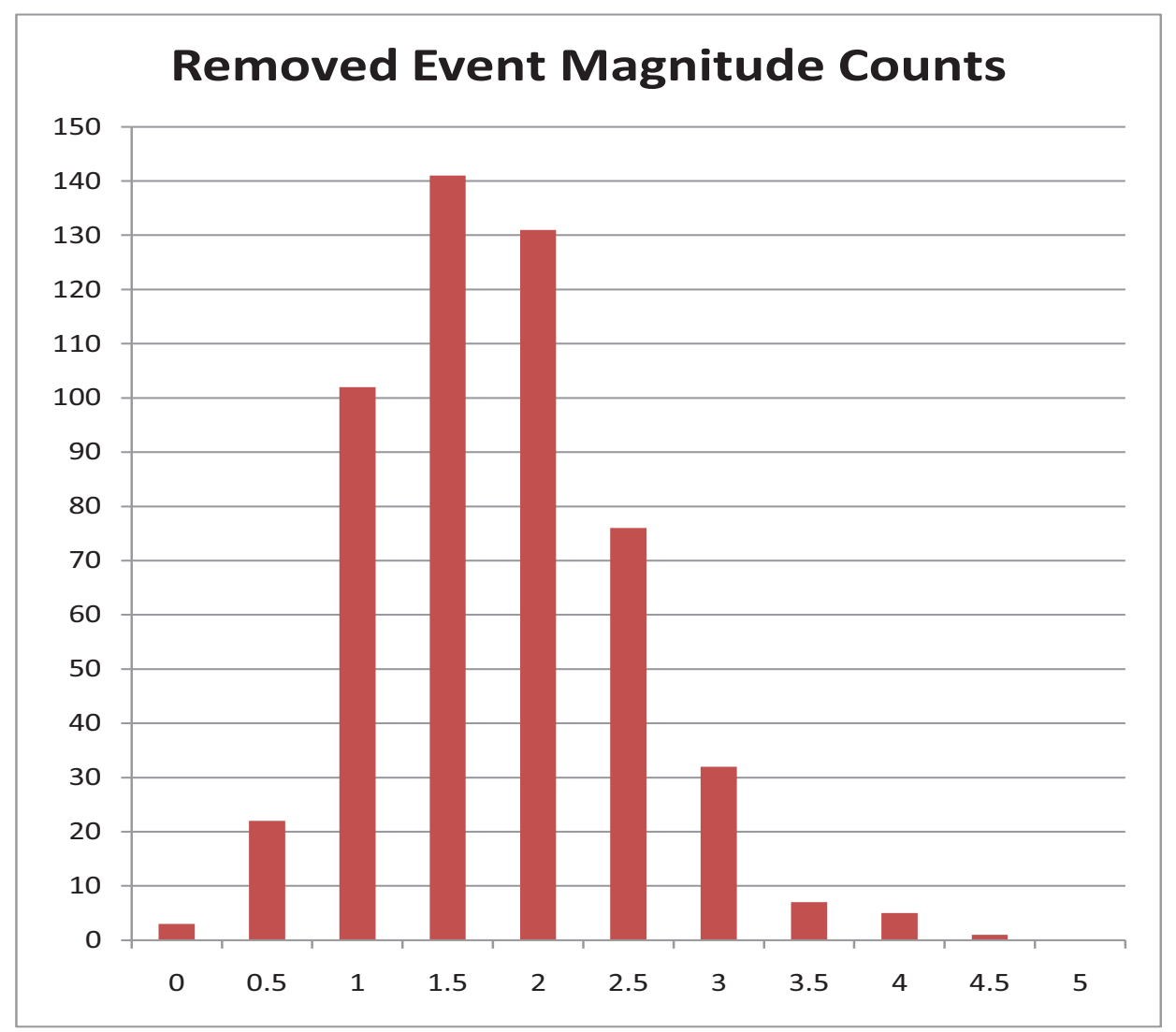

Figure 2.15 - Histogram on semi-log axes of the number of events in a given magnitude range that were removed from the UU-HUSEN catalog because they were considered to be biased locations due to the earthquake location procedure. See figure 2.9 for the locations of these events. 


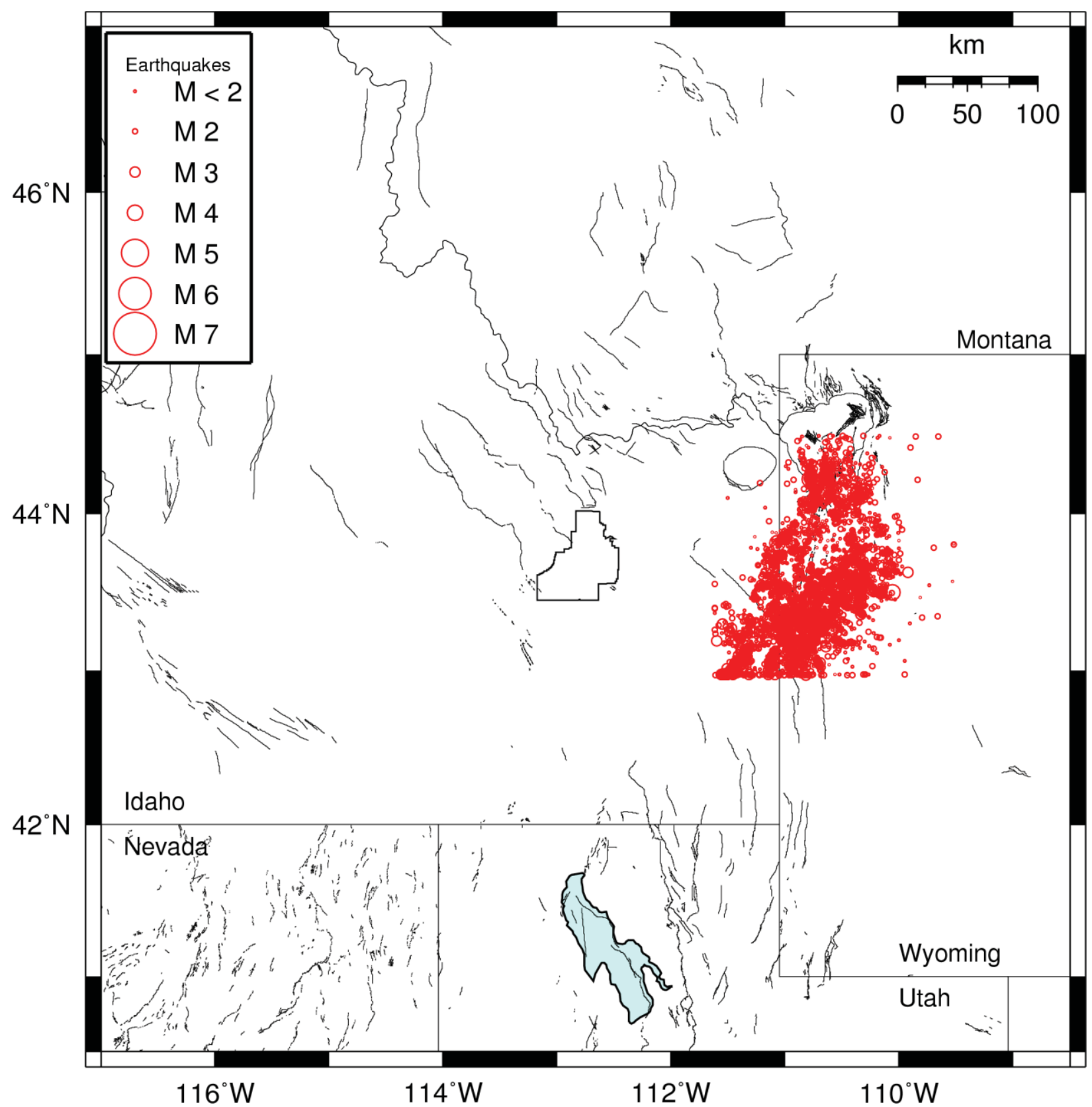

Figure 2.16 - Map of all events in the WHITE catalog (1986-2002) used in the creation of the INL18502007 compilation. Symbols are as in figure 2.1. 


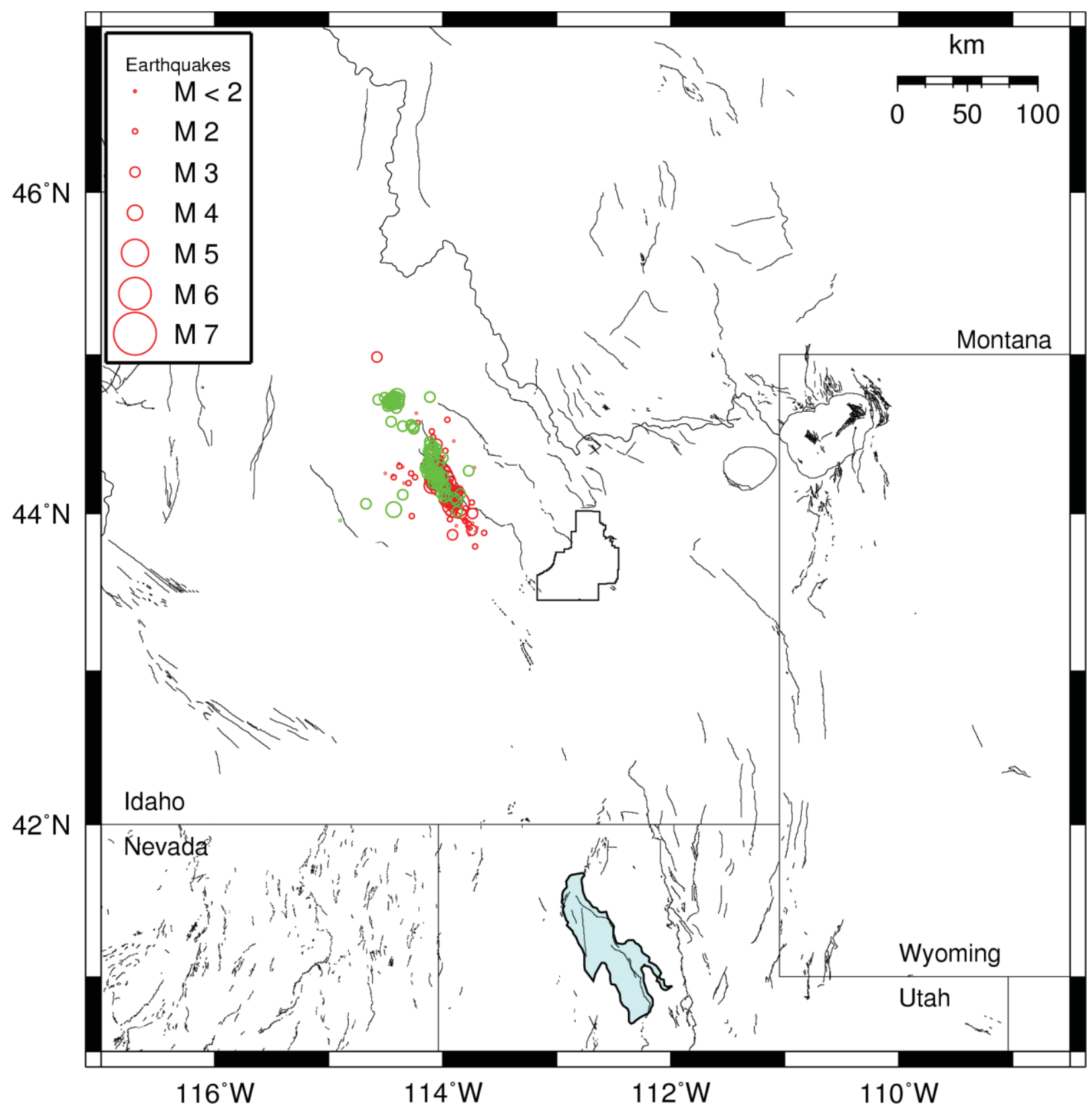

Figure 2.17 - Map of all events in the RICHINS catalog (red) and ZOLL_85 (green) catalog used in the creation of the INL1850-2007 compilation. Symbols are as in figure 2.1. 


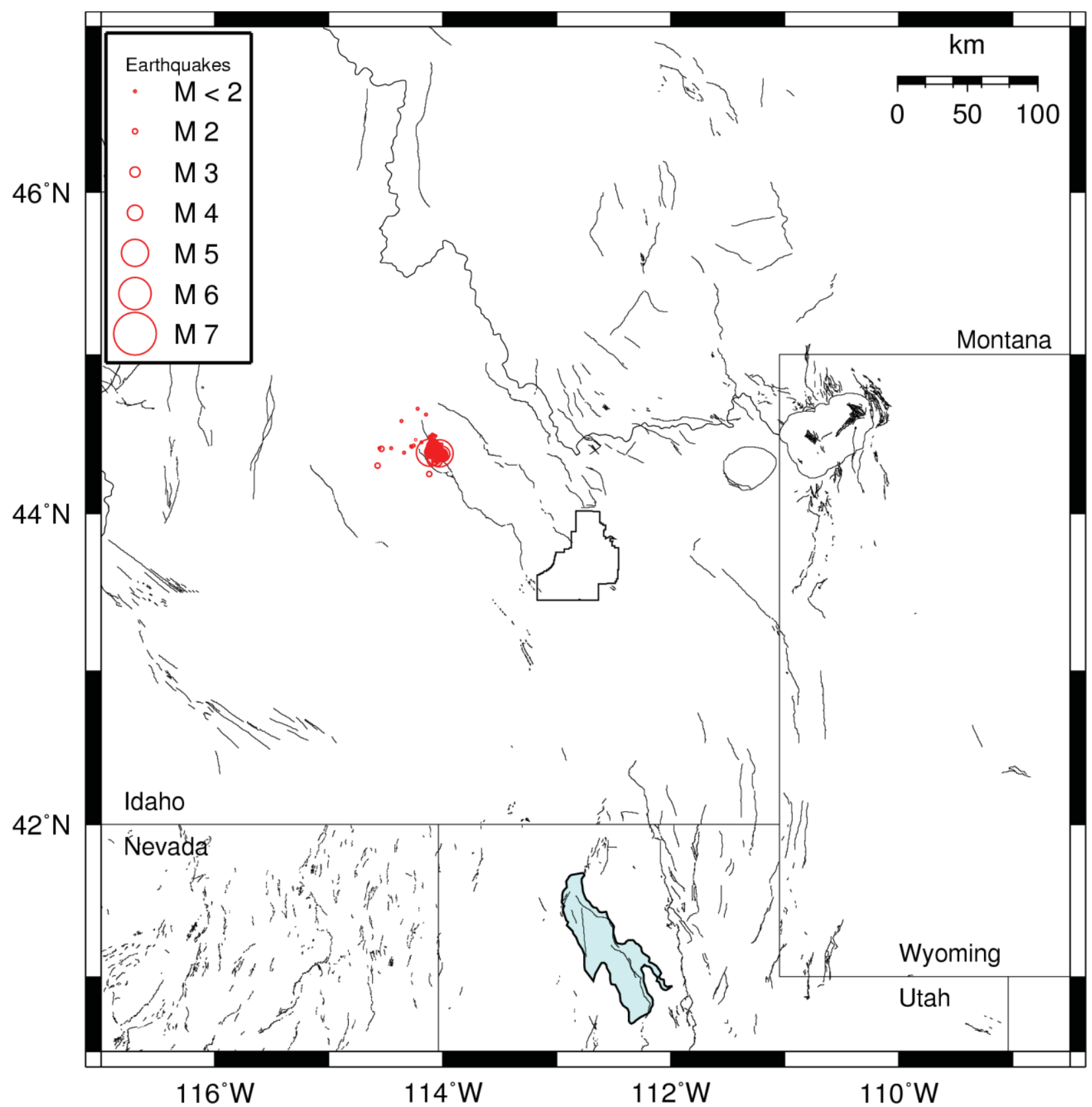

Figure 2.18 - Map of all events in the ZOLL_94 catalog used in the creation of the INL1850-2007 compilation. Symbols are as in figure 2.1. 


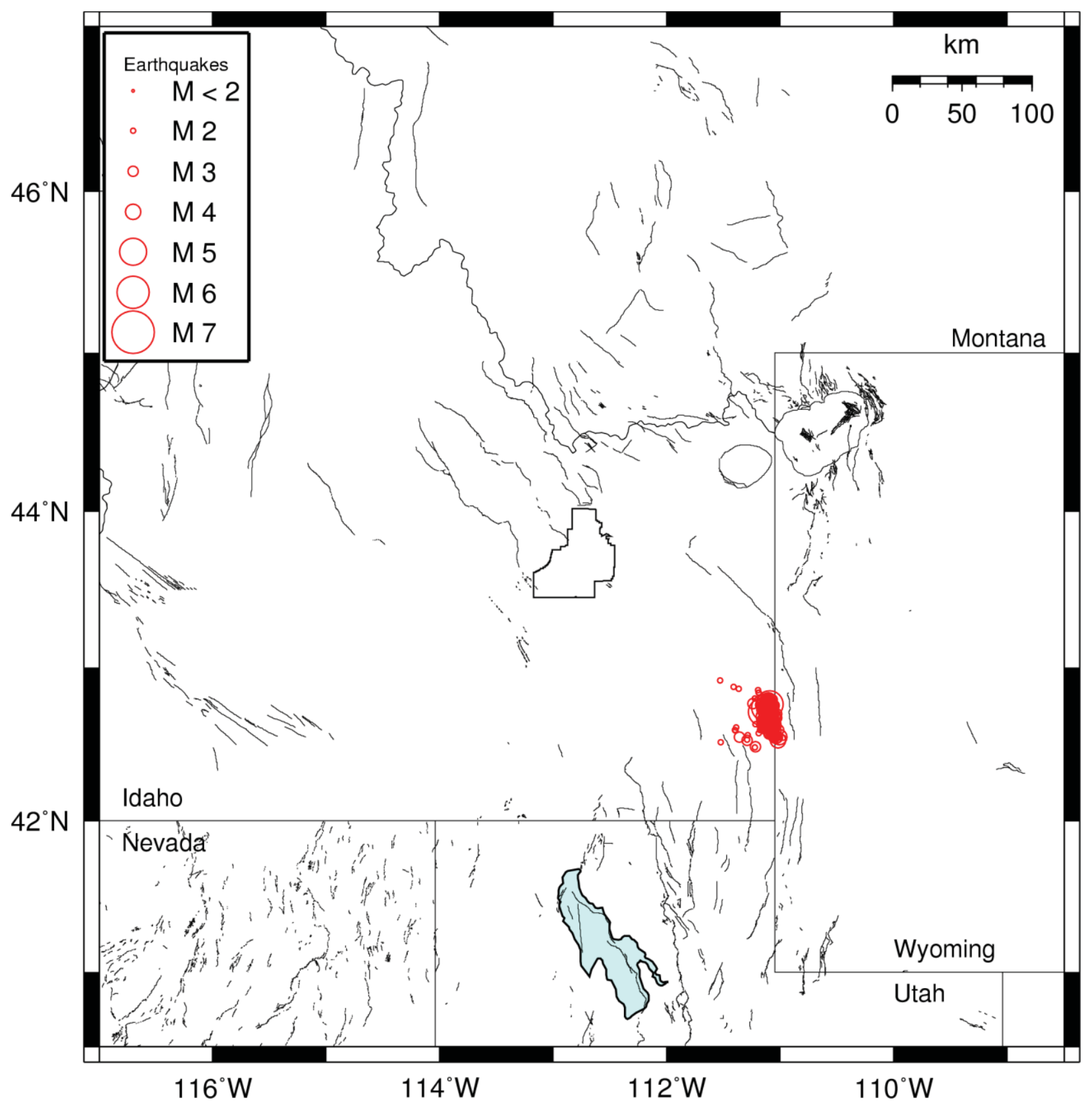

Figure 2.19 - Map of all events in the UU-BRUMB catalog used in the creation of the INL1850-2007 compilation. Symbols are as in figure 2.1. 


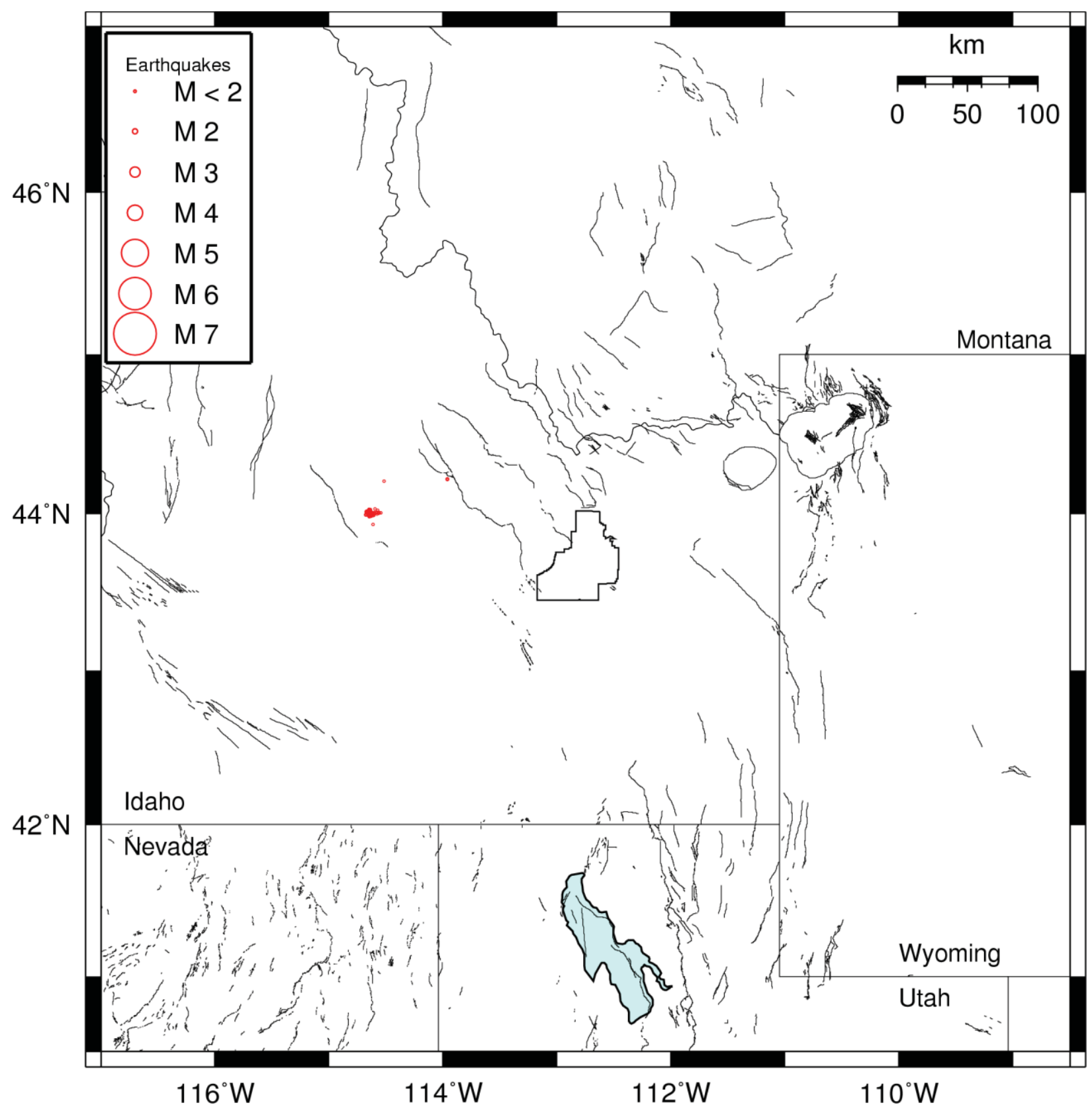

Figure 2.20 - Map of all events in the JACKSON catalog used in the creation of the INL1850-2007 compilation. Symbols are as in figure 2.1. 


\section{Input Catalog Preparation}

Prior to producing the final INL1850-2009 compilation, input catalogs went through several preprocessing procedures. First, the catalogs were formatted to a common-format. Second, catalogs were searched for redundant earthquake records. And third, the catalogs were merged into a single file. These steps were designed to facilitate producing the final catalog from the input catalogs, including selecting preferred events from sets of redundant events and preserving all available unique magnitude information for each event. The processing of each contributed catalog is discussed below.

\subsection{Input Catalog Formatting}

Prior to being merged together, all contributed catalogs were converted into a common format which simplified further processing. As part of this, event attributes were converted into a common convention with common units, when possible, and all available location and quality parameters were preserved. Formatting involved translating the following catalog-record attributes (Table 3.1): origin time, latitude, longitude, depth, magnitude, magnitude-type, magnitude-source, number of stations, number of arrivaltime observations (phases), azimuthal data gap, minimum station-event distance, root-mean-square arrival-time misfit, horizontal formal error, vertical formal error, location quality, and earthquake parameter-source. The fixed-format records were structured as in Table 3.1 with a single whitespace between each field. While most parameters are self explanatory and formatting them was straightforward, several of the record parameters warrant further comment and are discussed below.

\subsubsection{Event Depths}

Unless information to the contrary was available for each input catalog, it is assumed that event depths are given with respect to local surface elevations. There were two catalogs for which this is known not to be the case: UU-HUSEN and UU-WHITE. Depths in these catalogs are given with respect to sea level (Farrell, 2009) and an elevation correction was added to depths in each to make them consistent with the rest of the compilation: For the UU-HUSEN catalog, $2.4 \mathrm{~km}$ was added to each event depth, which corresponds to the average elevation of the Yellowstone Plateau (CVO, 2009). For the UUWHITE catalog, $2.3 \mathrm{~km}$ was added to each event depth, which corresponds to the average elevation in the region of the operative network (White, 2006).

\subsubsection{Depth Qualifier and Data sources}

For all input catalogs, common Qz; magnitude source and EQ_src; and Data_src conventions were employed. The Qz convention is defined in Table 3.7; the magnitude source and EQ_src codes are defined in Table 3.8; and the Data_src codes are defined in Table3.9.

\subsubsection{Magnitude Types}

For most input catalogs, event magnitudes are either explicitly included in the catalog or catalog header, or disclosed by the contributing institution. For the special study catalogs, however, each catalog was assumed that magnitudes were duration magnitude $\left(\mathrm{M}_{\mathrm{d}}\right)$, excepting the ZOLL_94 catalog which was assumed as local magnitude $\left(\mathrm{M}_{\mathrm{L}}\right)$ (Payne et al., 2004).

\subsubsection{Location Formal Errors}

Location errors, ERH (horizontal error) and ERZ (vertical error), determined by the earthquakelocation contributor, are produced by earthquake location routines. It is not known if these routines 
output formal errors based on the same confidence bounds. Excepting those given in the UU-HUSEN and UU-WHITE catalogs which had to be converted from ERX and ERY to ERH (as in Eaton et al., 1970), the ERH and ERZ fields were not altered by the formatting routines. That there is potentially discrepancy in these fields in the final, merged catalog, should be noted. However, this had no affect on events' inclusion in or exclusion from the final catalog (refer to Section 4).

\subsubsection{Location Quality Parameter, Q}

The quality parameter, Q, is most commonly adopted from the HYPO71 convention (Lee and Lahr, 1975), but the Qs (travel-time residual quality) and Qd (station distribution quality) parameters were kept separate (rather than averaged as is typically done) to make use of all available quality information and because some catalogs only give information about either Qs or Qd, but not both. Tables 3.2 and 3.3 define the Q parameters, Qs and Qd, respectively, used in most catalog records. For reasons discussed in Section 3.1.4, Q-values calculated from record attributes in Tables 3.2 and 3.3 may be inconsistent, however. That there is potentially discrepancy in these fields in the final, merged catalog should be noted. However, this had no affect on events' inclusion in or exclusion from the final catalog (refer to Section 4.2).

The Q parameters for several URS-ISB1 records differ from the HYPO71 convention. These were established by Askew and Algermisssen (1983) and are defined in Table 3.4. These Q-codes populated the Qs fields (with Qd set to NULL) in the formatted URS-ISB1 catalog and they apply to earthquakes with EQ_src of SRA for years prior to 1978. Also, the NEIC and PNSN catalogs each employed different Q-conventions which are included in Tables 3.5 and 3.6, respectively. With regard to the NEIC catalog, location quality attributes Qs and Qd of '..' do not represent null values. Rather, '..' indicates that the epicenter and depth uncertainties are less than $8.5 \mathrm{~km}$. Additionally, there two codes, J and L, which are unknown, but both have an EQ_src of UNR. Each appears only once in the catalog: J for a year 1901 event; L for a 1915 event.

\subsection{Preliminary Searches for Redundant Events within and between Input Catalogs}

It is possible that individual catalogs might have duplicate, or redundant events (i.e., more than one record for a single earthquake). Therefore, a search for duplicate events was performed wherein each input catalog was inspected for redundant events by searching for epicenters separated by at most $20 \mathrm{~km}$ of each other and corresponding origin-time differences of at most $3.5 \mathrm{~s}$. These criteria are more conservative than those employed by the ANSS (Advanced National Seismic System; 2009b) of $100 \mathrm{~km}$ and $16 \mathrm{~s}$ which could exclude aftershocks or events within a swarm, especially in the Yellowstone area. The maximum offset of $20 \mathrm{~km}$ is based on an approximated maximum event location uncertainty of $+/-10$ $\mathrm{km}$ for two locations determined by different institutions for the same earthquake. And, the time difference of $3.5 \mathrm{~s}$ corresponds to the average travel time for a compression-phase (P-phase) arrival to traverse a horizontal distance of $20 \mathrm{~km}$ through three different crustal velocity models in the surrounding region (Payne et al., 2008). The following catalogs had redundant events which were removed: MBMG, URS-ISB1, UUSS-WY, WHITE (relocated Teton catalog); and HUSEN (relocated Yellowstone catalog).

\subsubsection{Preferred-Event Selection Hierarchy}

To select a preferred event from sets of duplicate events, the following steps, shown in figure 3.1, were carried out by the duplicate-search procedure: First, it is determined if any epicenters lie within an authoritative region (discussed below). If duplicates are found to fall within an authoritative region, then one of two processing steps occurs: 
1. If there was only one within an authoritative region, then that is the preferred event.

2. If there were more than one, the original duplicate-event list is reduced to just those evids and the reduced set is further processed.

Second, if the preferred event was not yet selected, it was then chosen based on location quality attributes, listed in the order in which they are considered to better represent location quality:

1. GAP, minimal azimuthal separation between stations with arrivals for an event.

2. Dmin, minimum distance between an epicenter and the station recording the first arrival.

3. N-phs, the number of phases used to locate an event.

4. N-sta, the number of stations used to locate an event.

5. RMS, the root-mean-square arrival-time residuals.

6. Q, the location quality as determined by HYPO71 (Lee and Lahr, 1975).

For GAP, Dmin, and RMS, the lowest values were selected, which indicate that one event has better azimuth coverage, stations are closer to the epicenter, and the arrival times are a better fit to those predicted from the origin time and event location, respectively. For N-phs and N-sta, higher values were selected indicating the event was well-recorded. For the location quality, Q, the event with the Qs and Qd combination closest to "AA" (i.e., highest quality) was selected suggesting a better constrained event location.

With regard to the selection parameters, the following is a discussion of why the hierarchy was ordered as listed above. GAP is considered to be the best indicator of a solution's epicentral (horizontal) location quality because it is a measure of how well an event was surrounded by observing stations. While Dmin may indicate how well an event's depth may be resolved, it does not necessarily reflect how well the epicenter was constrained: the epicenter of an event with a large GAP and small Dmin can be illconstrained which could result in an earthquake being located within the incorrect zone in the sourcezonation models (Section 2.3). Both GAP and Dmin can be used to compare which event in a set of redundant events had better geometrical coverage which is considered to be a more reliable assessment of location quality than any other event attributes.

Next in the hierarchy are the event attributes that quantify the number of observations used to locate an earthquake: N-phs and N-sta. N-phs was preferred over $\mathrm{N}$-sta in the selection hierarchy for two reasons. Firstly, the N-phs attribute was more commonly included in the input catalogs than N-sta. Therefore, it could more reliably be used as a selection parameter. Secondly, for two events with the same GAP and Dmin, the one with more phases is considered more likely to be better located as both have equal or similar geometrical coverage.

The final event attributes included in the hierarchy are RMS and Q. While RMS may tradeoff with N-phs and N-sta (as the number of observations increases - thus increasing solution quality - RMS also likely increases), this parameter was included in the hierarch and implemented before Q because catalogs more commonly include this location-quality attribute than $\mathrm{Q}$. The best $\mathrm{Q}$ attribute was determined by selecting the event with the best Qs and Qd parameters as defined in Lee and Lahr (1975) and others as in Tables 3.2 through 3.6. This parameter was included in the preferred-event-selection process because Q is, in part, calculated from the formal errors (ERH - maximum horizontal error; ERZ - vertical error) as determined from the linearized least-squares location calculation which were not included in the hierarchy because not all input catalogs list estimates of the formal errors. This parameter was last in the hierarchy, 
however, because there is some variation in how $\mathrm{Q}$ is defined between catalogs which can lead to an inconsistent comparison of the Q attributes from different sources.

Implicit in the selection of the particular event attributes included in this selection hierarchy is that differences in the methods employed for earthquake location determinations and in the quantification of the location errors, as determined by differing sources or networks, are insignificant compared to the actual hierarchy used in the preferred-event selection process. Included in this assumption is that the event location quality is adequately quantified by the parameters discussed herein and that differences in the arrival quality due seismic waveform character (including differences related to impulsive versus emergent seismic arrivals), as identified by differing sources or networks, are insignificant in comparison. In an update, these assumptions could be evaluated and the effort to make this assessment - including gathering all available information about each arrival-time pick used for each earthquake location - could be carried out. Also assumed is that the velocity models used by different institutions for earthquake location determination adequately represents the velocity structure in their respective region (i.e. between the source and the recording stations). In an update, this assumption could be evaluated and the effort to make this assessment - including gathering the relevant velocity-model data, assessing how the models were generated, etc. - could be carried out.

\subsubsection{Authoritative Regions}

During the duplicate-event search, while determining a preferred event, one or more redundant events may fall within an authoritative region. The significance of these regions is that if an institution locates an earthquake within the region in which it is authoritative, the location solution which it generates is considered to be the authoritative, or preferred, solution. Authoritative region definitions were adopted from those defined by the ANSS (2009b). Additionally, authoritative regions were assigned to two other networks: INL (Payne et al., 2008) and the Jackson Lake Network (White, 2006; White et al., 2009). Figure 3.2 shows the locations and geometry of the authoritative regions. While network configurations have changed over time (stations added, removed, or moved), the authoritative region based preferredevent selection was applied using regions that do not change through time. This is because events located within an authoritative region should, currently and historically, have been best covered (in azimuth and with minimum distance from the event to the closest station) by the corresponding authoritative network. Events within a particular authoritative region would therefore have been best located by the corresponding authoritative network.

The geometries of the authoritative regions which were previously undefined, INL and JLNET, were chosen based on station locations, were chosen to abut adjacent, pre-existing authoritative regions, and the geometry was made to be as simple as possible. Figure 3.3 shows these regions and the locations of seismic stations used to define the regions. The JLNET region was defined strictly by the stations associated with that network (yellow and orange in figure 3.3). For the INL, excepting the JLNET stations (yellow), all stations plotted in figure 3.3 are monitored by the INL and were used to define the its region. The defining coordinates of both polygons were held fixed through the duration of the catalogs.

During this preliminary duplicate search, selecting an event based on authoritative-regions was particularly useful for redundant-event searches within the URS-ISB1 catalog as it included event

locations supplied by multiple institutions. Authoritative regions were more useful for the final duplicate search performed on the merged catalog (see Section 4). 


\subsubsection{Unaddressed Potential Redundancies}

There are several sets of potentially redundant events that remain in the formatted URS-ISB1 catalog and in the final INL1850-2007 compilation. Events in older catalogs were entered by hand, rather than by automated routines, and there can be human-errors, which appears to be the case with these event pairs. Table 3.10 shows several pairs of events which were found by random inspection (a non-exhaustive search). These pairs were not detected by the automated duplicate-search routine because the origin-time differences were much larger than the parameter values implemented (see Section 3.2).

\subsection{Catalog Merging}

After removing redundant events from the formatted input catalogs, the revised catalogs were concatenated into a single file of 107,347 records. Merging the input catalogs involved the following steps:

1. Concatenate all catalogs in a single file.

2. Sort the file by origin time.

3. Assign each record in the sorted file a unique event id.

Table 3.11 shows the updated fixed-format structure of the catalog after it has assigned event ids (field evid). Figure 3.4 shows a map of all 107,347 events in the merged, concatenated catalog. 
Table 3.1. Formatted input catalog record structure

\begin{tabular}{|c|c|c|c|c|c|}
\hline Field Name & Definition (units) & Format $(\mathrm{d}=$ digit; $\mathrm{s}=$ string $)$ & Column & Length & Null-value \\
\hline Origin_time & Earthquake date and time & $\begin{array}{l}\text { date: YYYY-MM-DD } \\
\text { time: HH:MM:SS.SS }\end{array}$ & 1 & 22 & $\mathrm{~N} / \mathrm{A}$ \\
\hline Lat & Earthquake location latitude (decimal degrees) & dd.ddd & 24 & 6 & $\mathrm{~N} / \mathrm{A}$ \\
\hline Lon & Earthquake location longitude (decimal degrees) & -ddd.ddd & 31 & 8 & $\mathrm{~N} / \mathrm{A}$ \\
\hline Depth & Earthquake focal depth $(\mathrm{km})$ & ddd.dd & 40 & 6 & Whitespaces \\
\hline $\mathrm{Qz}$ & Depth qualifier & Ss & 47 & 2 & Whitespaces \\
\hline Mag_1 (magnitude) & Earthquake Magnitude \#1 & (-)dd.dd & 49 & 5 & Whitespaces \\
\hline Mag 1 (mag. type) & Magnitude \#1 type & SS & 55 & 2 & Whitespaces/UK \\
\hline Mag 1 (mag. source) & Magnitude \#1 source & SSSSSS & 58 & 6 & Whitespaces/MAK \\
\hline Mag_2 (magnitude) & Earthquake Magnitude \#2 & (-)dd.dd & 65 & 5 & Whitespaces \\
\hline Mag 2 (mag. type) & Magnitude \#2 type & SS & 71 & 2 & Whitespaces/UK \\
\hline Mag_2 (mag. source) & Magnitude \#2 source & SSSSSS & 74 & 6 & Whitespaces/MAK \\
\hline Mag_3 (magnitude) & Earthquake Magnitude \#3 & (-)dd.dd & 81 & 5 & Whitespaces \\
\hline Mag_3 (mag. type) & Magnitude \#3 type & SS & 87 & 2 & Whitespaces/UK \\
\hline Mag_3 (mag. source) & Magnitude \#3 source & SSSSSS & 90 & 6 & Whitespaces/MAK \\
\hline I & Maximum Modified Mercalli Intensity (MM) & $\mathrm{d}$ & 97 & 1 & Whitespace \\
\hline N-obs (sta) & Number of stations used to calculate hypocenter & ddd & 99 & 3 & Whitespaces \\
\hline N-obs (phs) & Number of phases used to calculate hypocenter & ddd & 103 & 3 & Whitespaces \\
\hline GAP & $\begin{array}{l}\text { Maximum azimuthal gap in observing stations } \\
\text { (decimal degrees) }\end{array}$ & ddd & 107 & 3 & Whitespaces \\
\hline Dmin & Distance from epicenter to closest station $(\mathrm{km})$ & ddd.d & 111 & 4 & Whitespaces \\
\hline RMS & Root-mean-square travel-time residual (s) & d.dd & 117 & 4 & Whitespaces \\
\hline ERH & Standard horizontal location error $(\mathrm{km})$ & ddd.dd & 122 & 6 & Whitespaces \\
\hline ERZ & Standard vertical location error $(\mathrm{km})$ & ddd.dd & 129 & 6 & Whitespaces \\
\hline Q (Qs) & Location quality (see data source for details) & $\mathrm{s}$ & 136 & 1 & $\begin{array}{l}\text { Period }(.)- \\
\text { excepting NEIC }\end{array}$ \\
\hline $\mathrm{Q}(\mathrm{Qd})$ & Location quality (see data source for details) & $\mathrm{s}$ & 137 & 1 & $\begin{array}{l}\text { Period }(.)- \\
\text { excepting NEIC }\end{array}$ \\
\hline EQ_src (loc) & Earthquake location source & SSSSSS & 139 & 6 & Whitespaces \\
\hline EQ_src (time) & Earthquake origin-time source & SSSSSS & 146 & 6 & Whitespaces \\
\hline Data src (time) & Catalog source of data & SSSSSSSS & 153 & 8 & $\mathrm{~N} / \mathrm{A}$ \\
\hline Comments & Comments & arbitrary & 163 & arbitrary & Blank \\
\hline
\end{tabular}


Table 3.2. Quality parameter Qs definition

\begin{tabular}{|l|l|l|l|}
\hline Qs Code & RMS $(\mathrm{s})$ & ERH $(\mathrm{km})$ & ERZ $(\mathrm{km})$ \\
\hline A & $<0.15$ & $\leq 1.0$ & $\leq 2.0$ \\
\hline B & $<0.30$ & $\leq 2.5$ & $\leq 5.0$ \\
\hline C & $<0.50$ & $\leq 5.0$ & \\
\hline D & Others & & \\
\hline
\end{tabular}

Table 3.3. Quality parameter Qd definition

\begin{tabular}{|l|l|l|l|}
\hline Qd Code & N-obs (phs) & GAP & Dmin $(\mathrm{km})$ \\
\hline A & $\geq 6$ & $\leq 90^{\circ}$ & $\leq$ Depth or $5 \mathrm{~km}$ \\
\hline B & $\geq 6$ & $\leq 135^{\circ}$ & $\leq 2 \mathrm{x}$ Depth or $10 \mathrm{~km}$ \\
\hline C & $\geq 6$ & $\leq 180^{\circ}$ & $\leq 50 \mathrm{~km}$ \\
\hline D & Others & & \\
\hline
\end{tabular}

Table 3.4. Other quality codes in URS-ISB1 catalog for events with EQ_src of SRA for years prior to 1978

\begin{tabular}{|l|l|}
\hline Q Code & Definition \\
\hline A & Instrumental epicenter estimated to be good within $0.1^{\circ}$ \\
\hline B & Instrumental epicenter estimated to be good within $0.1^{\circ}$ to $0.2^{\circ}$ \\
\hline C & Instrumental epicenter estimated to be good within $0.2^{\circ}$ to $0.5^{\circ}$ \\
\hline D & Instrumental epicenter estimated to be good within $0.5^{\circ}$ to $1.0^{\circ}$ \\
\hline $\mathrm{E}$ & Instrumental epicenter estimated to be in error by more than $1.0^{\circ}$ \\
\hline $\mathrm{F}$ & Epicenter from felt data estimated to be good to $0.5^{\circ}$ \\
\hline $\mathrm{G}$ & Epicenter from felt data estimated to be good to $0.5^{\circ}$ to $1.0^{\circ}$ \\
\hline $\mathrm{H}$ & Epicenter from felt data estimated to be good to $1.0^{\circ}$ to $2.0^{\circ}$ \\
\hline $\mathrm{I}$ & Epicenter from felt data estimated to be in error by more than $2.0^{\circ}$ \\
\hline
\end{tabular}

Table 3.5. NEIC quality code definitions

\begin{tabular}{|l|l|l|}
\hline Q Type & Code & Definition \\
\hline Qs & $\%$ & $\begin{array}{l}\text { A non-furnished hypocenter has been computed using data reported by a } \\
\text { single network of stations for which the data and/or origin time cannot be } \\
\text { confirmed from seismograms available to NEIC analysts. All other } \\
\text { parameters are considered to be consistent with normal NEIC publication } \\
\text { criteria. }\end{array}$ \\
\hline & $*$ & $\begin{array}{l}\text { Less reliable hypocenter determination by the PDE using incomplete or less } \\
\text { reliable data. Beginning in January 1985, in general, the geometric mean of } \\
\text { the semi-major and semi-minor axes of the horizontal 90\% confidence ellipse } \\
\text { is greater than 8.5 km and less than or equal to 16.0 km. }\end{array}$ \\
\hline Qd & $\begin{array}{l}\text { Poor solution - accuracy is considered to be below normal NEIC publication } \\
\text { criteria. Beginning in January 1985, in general, the geometric mean of the } \\
\text { semi-major and semi-minor axes of the horizontal 90\% confidence is greater } \\
\text { than 16.0 km. This includes a poor solution computed using data reported by } \\
\text { a single network. }\end{array}$ \\
\hline & $\begin{array}{l}\text { Poor depth estimate; depth accuracy is estimated to be greater than } 16 \mathrm{~km} \\
\text { based on the } 90 \% \text { confidence ellipse. }\end{array}$ \\
\hline
\end{tabular}


Table 3.6. PNSN quality code definitions

\begin{tabular}{|l|l|}
\hline Q Code & Definition \\
\hline Qs & Based on travel time residuals (RMS) where: \\
& A if RMS $<15 \mathrm{~s}$ \\
& D if RMS $>0.5 \mathrm{~s}$ \\
& However, uncertainty of hypocenter location also affects Qs. \\
\hline Qd & Based on station distribution where: \\
& A if N-obs phs $\geq 8$, and GAP $\leq 90^{\circ}$, and Dmin $\leq 5 \mathrm{~km}$ or depth \\
& D if N-obs sta $\leq 5$, or GAP $>180^{\circ}$, or Dmin $>50 \mathrm{~km}$ \\
\hline
\end{tabular}

Table 3.7. Depth-qualifier parameter, Qz, definition

\begin{tabular}{|l|l|}
\hline Qz Code & Definition \\
\hline $\mathrm{G}$ & Depth restrained by a Geophysicist \\
\hline $\mathrm{H}$ & Hypocenter restrained because solution did not converge \\
\hline $\mathrm{R}$ & $\begin{array}{l}\text { Depth restrained } \\
\text { boor depth estimate; depth accuracy is estimated to be greater than } 16 \mathrm{~km}\end{array}$ \\
\hline 2 & based on the confidence ellipse \\
\hline
\end{tabular}


Table 3.8. Magnitude-source and EQ src definitions

\begin{tabular}{|c|c|}
\hline Source Code & Definition \\
\hline $\mathrm{AEC}^{*}$ & Atomic Energy Commission \\
\hline $\mathrm{BAS}^{\dagger}$ & Basham et al. (1979) \\
\hline $\mathrm{BGBK}^{*}$ & Berg and Baker (1963) \\
\hline BOLT $^{*}$ & Bolt (1984) \\
\hline $\mathrm{BOT}^{\dagger}$ & Bolt (1984) \\
\hline $\mathrm{BRK}^{*}$ & University of California at Berkeley \\
\hline BRUM & Brumbaugh (2001) \\
\hline $\mathrm{BSE}^{\dagger}$ & State University, Boise, ID, seismic station BSE \\
\hline $\mathrm{BSU}^{*}$ & Boise State University, Boise, ID \\
\hline BU & Undefined reference in URS-ISB1 Catalog \\
\hline $\mathrm{BUL}^{\dagger}$ & Montana Bureau of Mines and Geology, Butte, MT, seismic station BUT \\
\hline BUT & Montana Bureau of Mines and Geology, Butte, MT, seismic station BUT \\
\hline $\mathrm{CCN}^{*}$ & USGS Central California Network \\
\hline $\mathrm{CDL}^{*}$ & Carver et al. (1983) \\
\hline $\mathrm{CGS}^{*}$ & U.S. Coast and Geodetic Survey \\
\hline DEWEY $^{*}$ & Dewey (1987) \\
\hline DNAG $^{*}$ & Decade of North American Geology \\
\hline DOGAMI $^{*}$ & Oregon Department of Geology and Mineral Industries \\
\hline $\operatorname{DOS}^{\dagger}$ & Doser and Smith (1989) \\
\hline DOSER & Doser and Smith (1989) \\
\hline $\mathrm{EDS}^{*}$ & Earthquake Data Summary \\
\hline $\mathrm{EPB}^{*}$ & $\begin{array}{l}\text { Earth Physics Branch, Division of Seismology and Geothermal Studies, } \\
\text { Department of Energy, Mines and Resources, Ottawa, Canada }\end{array}$ \\
\hline $\mathrm{EQH}^{*}$ & Earthquake History of the United States \\
\hline ERD $^{*}$ & $\begin{array}{l}\text { U.S. Energy Research Division Administration and U.S. Atomic Energy } \\
\text { Commission }\end{array}$ \\
\hline ERL $^{*}$ & Environmental Research Laboratory (1971-1973) \\
\hline ESO & Earthquake Studies Office, Montana Bureau of Mines and Geology \\
\hline $\mathrm{GR}^{\dagger}$ & Gutenberg and Richter (1965) \\
\hline $\mathrm{GS}^{\dagger}$ & USGS \\
\hline HAN $^{*}$ & Hanford Catalog, Woodward-Clyde Consultants \\
\hline $\mathrm{HRV}^{\dagger}$ & CMT \\
\hline HUSEN & Husen and Smith (2004) \\
\hline IE & Idaho National Laboratory \\
\hline ISC $^{*}$ & International Seismological Centre \\
\hline $\mathrm{JLNET}^{\dagger}$ & Jackson Lake Network. Likely reference: O’Connell et al. (2003) \\
\hline $\mathrm{JON}^{\dagger}$ & Jones et al., 1975 \\
\hline $\mathrm{KJ}^{\dagger}$ & Kanamori and Jennings, 1978 \\
\hline MAK & Unknown Abbreviation in DNAG Catalog \\
\hline MBMG & Montana Bureau of Mines and Geology \\
\hline MB-BB & $\begin{array}{l}\text { Montana Bureau of Mines and Geology ("BB" magnitude attribute in Stickney } \\
\text { (2006), MBMG catalog). }\end{array}$ \\
\hline MMT $^{*}$ & Missoula, Montana \\
\hline $\mathrm{MSL}^{*}$ & Missoula, Montana \\
\hline $\mathrm{MSO}^{*}$ & Missoula, Montana \\
\hline NEIC & National Earthquake Information Center \\
\hline OSU* $^{*}$ & Oregon State University \\
\hline
\end{tabular}


Table 3.8. Continued

\begin{tabular}{|l|l|}
\hline Source Code & Definition \\
\hline OTT $^{*}$ & Ottawa, Canada \\
\hline PAS & Pasadena, CA \\
\hline PDE-W & NEIC PDE weekly listing \\
\hline PNSN & Pacific Northwest Seismic Network \\
\hline RAS $^{*}$ & Rasmussen (1966) \\
\hline REN $^{*}$ & Reno, Nevada \\
\hline SEA $^{*}$ & Seattle, WA \\
\hline SJG $^{\dagger}$ & Slemmons, Jones, and Gimlet, 1965 \\
\hline SLC & Salt Lake City, UT \\
\hline SLM & St. Louis, Missouri \\
\hline SRA & Stover, Reagor, and Algermissen \\
\hline UCGS $^{\dagger}$ & U.S. Coast and Geodetic Survey \\
\hline UNR $^{\dagger}$ & University of Nevada, Reno \\
\hline USBR $^{*}$ & U.S. Bureau of Reclamation \\
\hline USE $^{*}$ & U.S. Earthquakes, U.S. Coast and Geodetic Survey \\
\hline USG $^{*}$ & Undefined reference in URS-ISB1 Catalog \\
\hline USGS $^{*}$ U.S. Geological Survey \\
\hline USHIS $^{*}$ & Undefined reference in URS-ISB1 Catalog \\
\hline USN $^{*}$ & U.S. Network \\
\hline UUSS $^{*}$ & University of Utah Seismograph Stations \\
\hline WCC & Woodward-Clyde Consultants \\
\hline WHITE & White et al. (2009) \\
\hline WOOL & Woolard (1968) \\
\hline UU $^{\dagger}$ & University of Utah \\
\hline ZOLL & Jim Zollweg, BSU \\
\hline & Zollweg and Richins (1985) \\
\hline
\end{tabular}

${ }^{\dagger}$ Reference from Woodward-Clyde Federal Services et al. (1996)

$\$$ Reference from Wong (2010) 
Table 3.9. Source-catalog, Data_src, definitions

\begin{tabular}{|l|l|}
\hline Source Code & Definition \\
\hline INL2009 & Idaho National Laboratory 1973-2007 Catalog \\
\hline JACKSON & White Clouds catalog (Jackson and Zollweg, 1988) \\
\hline MBMG & Montana Bureau of Mines and Geology (Stickney, 2006) \\
\hline NEIC-PDE & $\begin{array}{l}\text { National Earthquake Information Center Preliminary Determination of } \\
\text { Epicenters catalog }\end{array}$ \\
\hline PNSN & Pacific Northwest Seismic Network (PNSN, 2009) \\
\hline RICHINS & Borah Peak Aftershock catalog (Richins et al., 1985; 1987) \\
\hline URS-ISB1 & URS ISB1 catalog (F. Terra, pers. comm., 2009a) \\
\hline UU-BRUMB & Draney Peak catalog (Brumbaugh, 2001) \\
\hline UU-HUSEN & Relocated Yellowstone Catalog (Husen and Smith, 2004) \\
\hline UU-WHITE & Relocated Teton Catalog (White et al., 2009) \\
\hline UUSS-UU & University of Utah Seismograph Stations Utah catalog (UUSS-UU, 2009) \\
\hline UUSS-WY & University of Utah Seismograph Stations Utah catalog (UUSS-WY, 2009) \\
\hline ZOLL_85 & Borah Peak Aftershock catalog (Zollweg and Richins, 1985) \\
\hline ZOLL_94 & Devils Canyon catalog (Zollweg, 1994; Payne et al., 2004) \\
\hline
\end{tabular}


Table 3.10. Examples of unaddressed, duplicate events in the URS-ISB1 catalog

\begin{tabular}{|c|c|c|c|c|c|c|c|c|c|c|}
\hline $\begin{array}{l}\text { Redundant } \\
\text { Pair }\end{array}$ & Date & Time & Lat & Lon & Depth & Mag_1 & Mag_2 & I & loc_src & time_src \\
\hline \multirow[t]{2}{*}{1} & 19171212 & 1050.0000 & 43.0000 & -111.3000 & .000 & $5.30 \mathrm{UK}$ JON & -9.99 & 5 & NEIC' & USHIS \\
\hline & 19171212 & 1150.0000 & 43.0000 & -111.3000 & .000 & 5.30 ML SRA & 5.30 ML REN & 5 & ...... & SRA \\
\hline \multirow[t]{2}{*}{2} & 19371118 & 2350.0000 & 42.1000 & -113.9000 & .000 & 5.40 ML REN & -9.99 & 0 & $\ldots \ldots$ & DNAG \\
\hline & 19371118 & 05020.0000 & 42.1000 & -113.9000 & .000 & $5.40 \mathrm{ML} \mathrm{SJG}$ & -9.99 & 4 & NEIC & USHIS \\
\hline \multirow[t]{2}{*}{3} & 1945918 & 2139.0000 & 40.6000 & -116.5000 & .000 & 5.10 UK PAS & -9.99 & 0 & ...... & DNAG \\
\hline & 1945918 & 2239.0000 & 40.6000 & -116.5000 & .000 & $5.10 \mathrm{ML} \mathrm{PAS}$ & 5.10 ML SRA & 4 & NEIC & SRA \\
\hline \multirow[t]{2}{*}{4} & 1963922 & 05036.100 & 44.3000 & -114.7000 & 15.000 & 4.20 MB NEIC & $4.19 \mathrm{MB}$ & 0 & $\ldots \ldots$ & DNAG \\
\hline & 1963922 & 05610.5000 & 44.3000 & -114.8000 & 15.000 & $4.20 \mathrm{MB}$ NEIC & $4.19 \mathrm{MB}$ & 57 & . . & DNAG \\
\hline
\end{tabular}


Table 3.11. Formatted output catalog record structure

\begin{tabular}{|l|l|l|l|}
\hline Field Name & Column & Length & Null-value \\
\hline evid & 1 & 7 & N/A \\
\hline Origin_time & 9 & 22 & N/A \\
\hline Lat & 32 & 6 & N/A \\
\hline Lon & 39 & 8 & N/A \\
\hline Depth & 48 & 6 & Whitespaces \\
\hline Qz & 55 & 2 & Whitespaces \\
\hline Mag_1 (magnitude) & 57 & 5 & Whitespaces \\
\hline Mag_1 (mag. type) & 63 & 2 & Whitespaces/UK \\
\hline Mag_1 (mag. source) & 66 & 6 & Whitespaces/MAK \\
\hline Mag_2 (magnitude) & 73 & 5 & Whitespaces \\
\hline Mag_2 (mag. type) & 79 & 2 & Whitespaces/UK \\
\hline Mag_2 (mag. source) & 82 & 6 & Whitespaces/MAK \\
\hline Mag_3 (magnitude) & 89 & 5 & Whitespaces \\
\hline Mag_3 (mag. type) & 95 & 2 & Whitespaces/UK \\
\hline Mag_3 (mag. source) & 98 & 6 & Whitespaces/MAK \\
\hline I & 105 & 1 & Whitespace \\
\hline N-obs (sta) & 107 & 3 & Whitespaces \\
\hline N-obs (phs) & 111 & 3 & Whitespaces \\
\hline GAP & 115 & 3 & Whitespaces \\
\hline Dmin & 119 & 4 & Whitespaces \\
\hline RMS & 125 & 4 & Whitespaces \\
\hline ERH & 130 & 6 & Whitespaces \\
\hline ERZ & 137 & 6 & Whitespaces \\
\hline Q (Qs) & 144 & 1 & Period (.) - excepting NEIC \\
\hline Q (Qd) & 145 & 1 & Period (.) - excepting NEIC \\
\hline EQ_src (loc) & 147 & 6 & Whitespaces \\
\hline EQ_src (time) & 154 & 6 & Whitespaces \\
\hline Data_src (time) & 161 & 8 & N/A \\
\hline Comments & 171 & arbitrary & Blank \\
\hline & & & \\
\hline
\end{tabular}




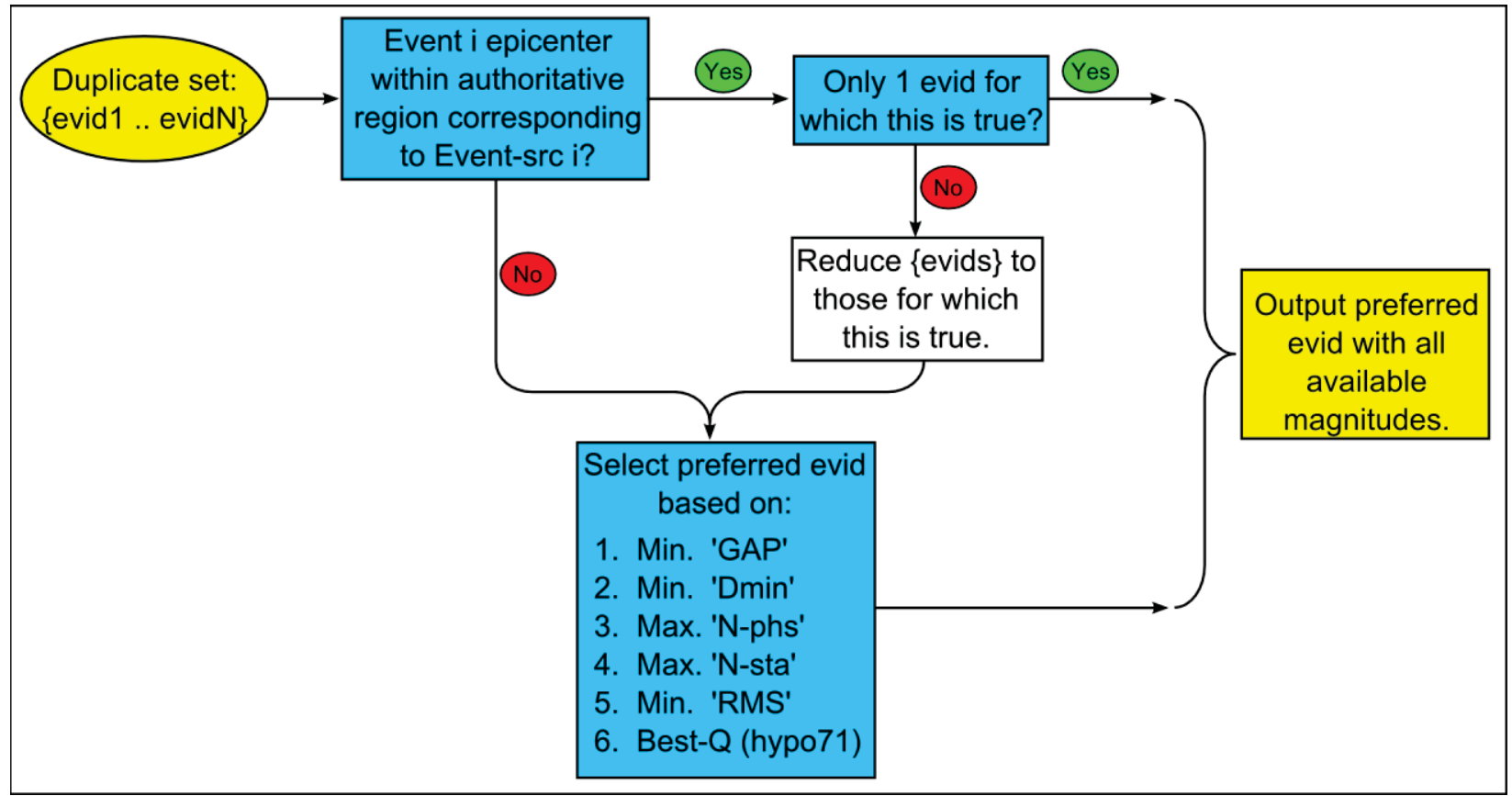

Figure 3.1 - Flowchart showing the logic used in selecting a preferred event from a list of redundant events for each input catalog. 


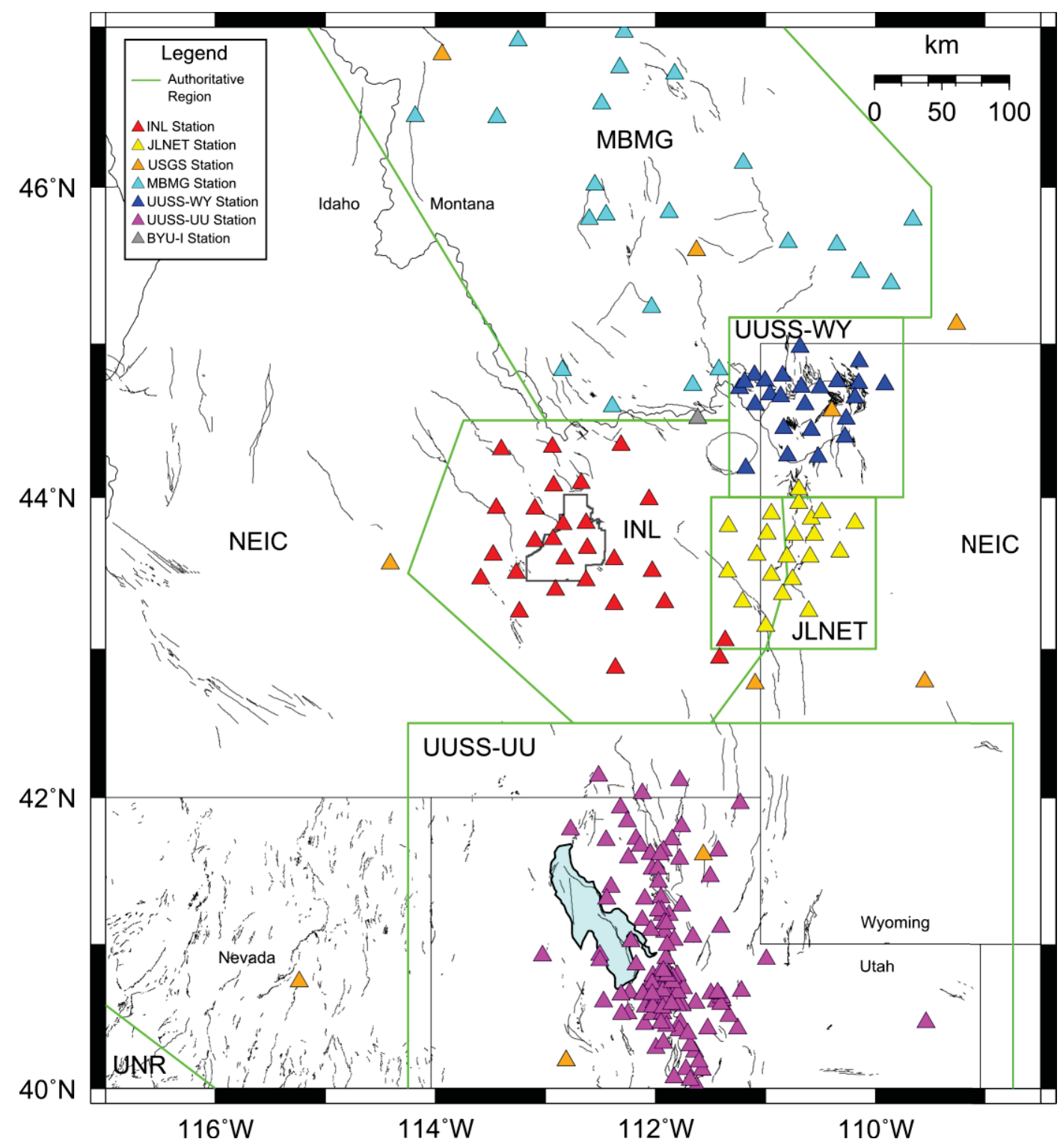

Figure 3.2 - Map showing the authoritative regions, green polygons and line segments, used to select preferred events from a set of duplicate events and the seismic stations (operating 2007) used in creation of the polygons. If one of the duplicate events is located with the authoritative region and the source of the event's location corresponds to that region, that event is preferred over other redundant events (refer to figure 3.2). Where the INL and JLNET regions overlap and during the time of the JLNET network operation, events were selected using location quality criteria as discussed in Section 3.2.1. 


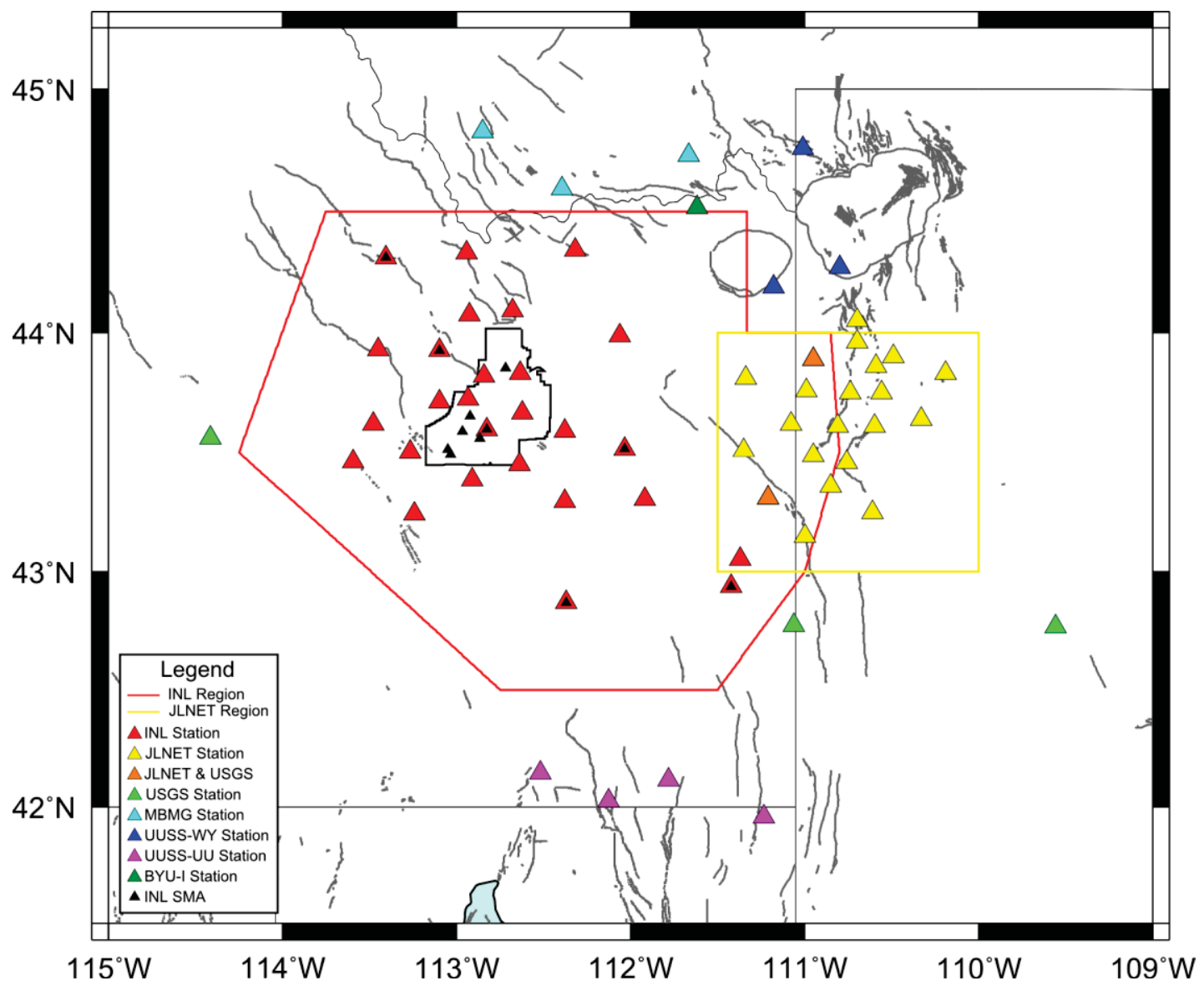

Figure 3.3 - Map showing derived authoritative regions, INL and JLNET, and the stations used to define those regions. The JLNET region was defined considering solely stations in yellow and orange, while the INL region was defined considering all stations, except those in yellow. Other symbols as in figure 2.1. 


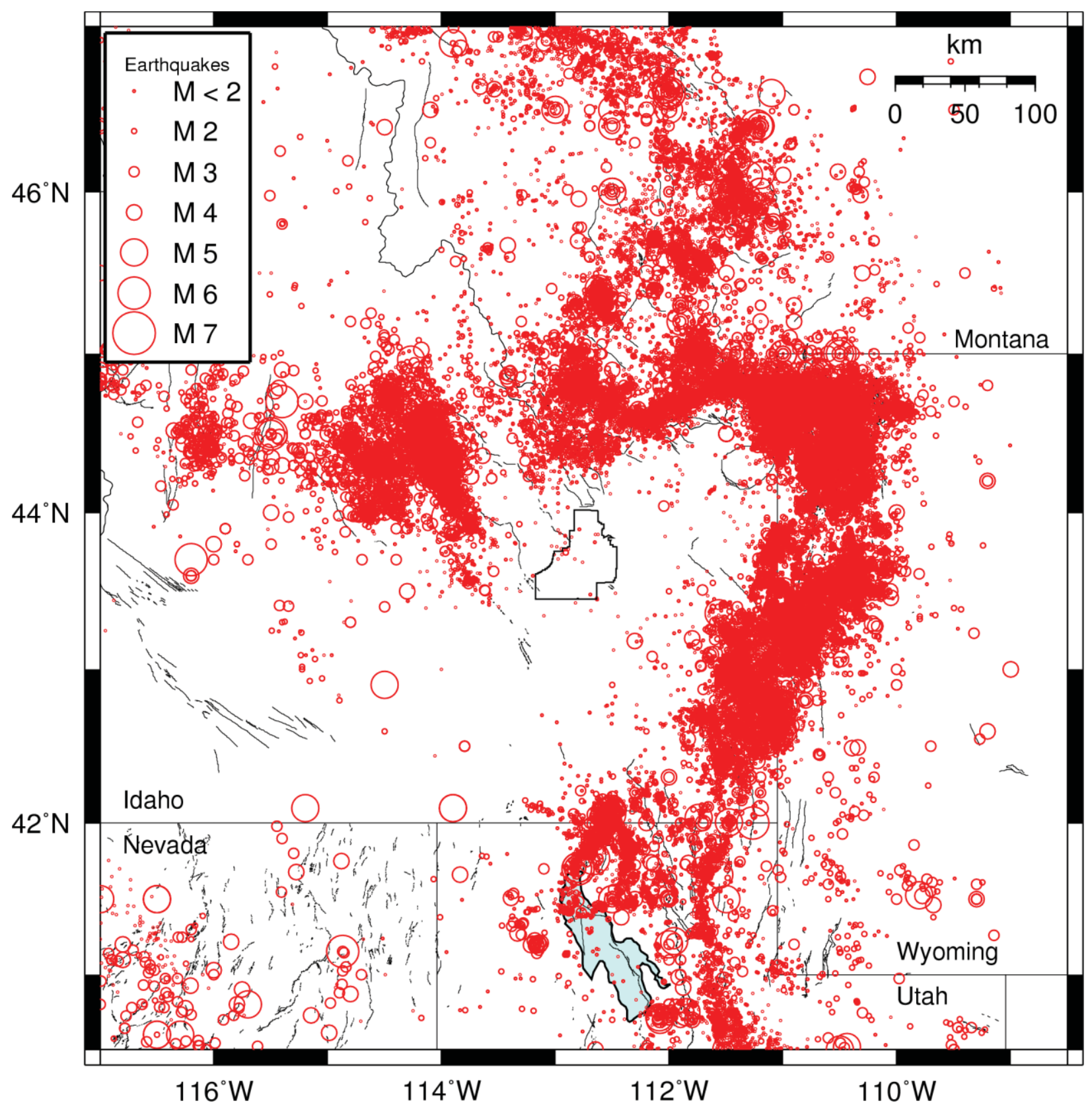

Figure 3.4 - Map of all events within the file of concatenated catalogs. Symbols are as in figure 2.1. 


\section{Final Redundant Event Removal}

After the input catalogs were formatted and merged into a single file, the duplicate search was repeated on this file. The same parameters were used to perform this duplicate search as discussed in section 3.2 (event separation of at most $20 \mathrm{~km}$ and origin-time differences of at most $3.5 \mathrm{~s}$ ) but the logic used was slightly more complex (figure 4.1). First, it is determined if any of the redundant events are from a preferred source catalog (section 4.1, below). If so, then one of two processing steps occurs: 1) If there was only one preferred-source event, then that is the preferred event. 2) If there were more than one, then the original event list is reduced to just those events with preferred-source sources and the reduced set is further processed. If there was not a single preferred-source event, then the duplicate-event processing continues as discussed in section 3.2 with the exception that after the authoritative-source check is performed, if one of the redundant events has source 'NEIC,' it is preferred prior to considering solution quality because 'NEIC' is considered authoritative for regions outside of individual network authoritative regions (ANSS, 2009b). Table 4.1 has final contributions to the INL1850-2007 compilation from each input source catalog.

As discussed previously, event records retain all unique magnitude information from their source catalogs. While compilation records are structured to hold three blocks of magnitude fields (where each block contains the triplet magnitude, magnitude type, and magnitude source), when more than three were available for a particular event, a subsequent record was created in the compilation for this event. The subsequent record contained solely the fields evid, Mag_1, Mag_2, and Mag_3, where Mag_2 and Mag_3 were populated if needed, and the structure was otherwise identical to a complete compilation record: the evid, Mag_1, Mag_2, and Mag_3 fields occupied the same columns and had the same field length as described in Table 3.1.

\subsection{Preferred Sources}

In performing the duplicate-event search, to determine a preferred event, sets of events were checked to see if any came from catalog sources which were selected to be preferred-sources. A catalog of events is considered a preferred-source catalog if it was generated by a special study in contrast to routine network processing. This is because, in general, a special study will apply more rigorous analysis to event locations rather than that by the routine analysis performed by monitoring networks. These studies include the White Clouds catalog (JACKSON); the Borah Peak aftershock catalogs: (RICHINS and ZOLL_85); the Devils Canyon catalog (ZOLL_94); the Draney Peak catalog (UU-BRUM); the relocated Teton catalog (UU-WHITE); and the relocated Yellowstone catalog (UU-HUSEN). An event from a preferred-source catalog is preferred over all non-preferred-source events in the duplicate list. Additionally, the routine was configured to always prefer an event from source INL2009 rather than URS-ISB1 because many event locations are updated and more information on the locations is now available in the INL2009 catalog than was available for development of the URS-ISB1, which previously incorporated INL events.

\subsection{Results}

From the original 107,346 records in the file of formatted, merged input catalogs (Section 3.3), 32,247 were found to be non-unique and were removed. The following lists how many times each step in the preferred-event selection hierarchy (figure 4.1) was used to ultimately determine a preferred-event: 
- 2,831 were selected from the INL2009 catalog because redundant events were only found in both the INL2009 and URS-ISB1 catalogs.

- 22,263 preferred events were selected from preferred sources (EQ_src - loc field) where the following lists how often each source was selected as the preferred source:

JACKSON 3 times

RICHINS 83 times

UU-BRUM 214 times

UU-HUSEN 20,602 times

UU-WHITE 1,252 times

ZOLL_85 89 times

ZOLL_94 22 times

- 86 preferred events were selected because they were located by the NEIC. These events are plotted in figure 4.2 showing that the events fall outside of the authoritative regions - excepting JLNET as these earthquake occurred outside of the time the JLNET network was operating - indicating that they would not be well-located by regional networks.

- 522 preferred events were selected because they had a minimum GAP.

- 1 preferred event was selected because it had the minimum Dmin.

- There were no cases where events were selected from steps lower than Dmin in the selection hierarchy (figure 4.1).

The difference between the total counts from the above list and the total duplicate count of 32,247 comes from sets of redundant events having more than two members. The above total-count list illustrates the ultimate mechanism employed to select the preferred event from all sets of redundant events.

It is notable that, even with the more aggressive ANSS duplicate-search parameter values (i.e., values that are more likely to mistakenly pair events together as duplicates) of $10 \mathrm{~km}$ and $16 \mathrm{~s}$ (see Section 3.2), only 514 more events were removed, with some obvious mis-pairing of events (e.g., a M 4.3 earthquake with a M 1.8 earthquake). Therefore, the catalog that was yielded by the applied procedure must consist predominantly of unique events. 
Table 4.1. Comparison of original catalog lengths to number of record contributions in the final INL1850-2007 compilation. There is a notable decrease in the number of events in URS-ISB1 catalog which is primarily the result of them being displaced by events in the preferred-source (Section 4.1) UUHUSEN catalog and secondarily by other preferred-source sources.

\begin{tabular}{|l|l|l|}
\hline Catalog & $\begin{array}{l}\text { Original Number } \\
\text { of Records }\end{array}$ & $\begin{array}{l}\text { Final Number of } \\
\text { Contributions }\end{array}$ \\
\hline INL2009 & 14,854 & 10,647 \\
\hline JACKSON & 191 & 191 \\
\hline MBMG & 11,776 & 9,852 \\
\hline NEIC-PDE & 209 & 118 \\
\hline PNSN & 302 & 249 \\
\hline RICHINS & 422 & 421 \\
\hline URS-ISB1 & 26,341 & 11,273 \\
\hline UU-BRUMB & 480 & 480 \\
\hline UU-HUSEN & 30,712 & 30,156 \\
\hline UU-WHITE & 8,505 & 8,337 \\
\hline UUSS-UU & 2,780 & 2,776 \\
\hline UUSS-WY & 11,855 & 173 \\
\hline ZOLL_85 & 113 & 111 \\
\hline ZOLL_94 & 314 & 314 \\
\hline
\end{tabular}




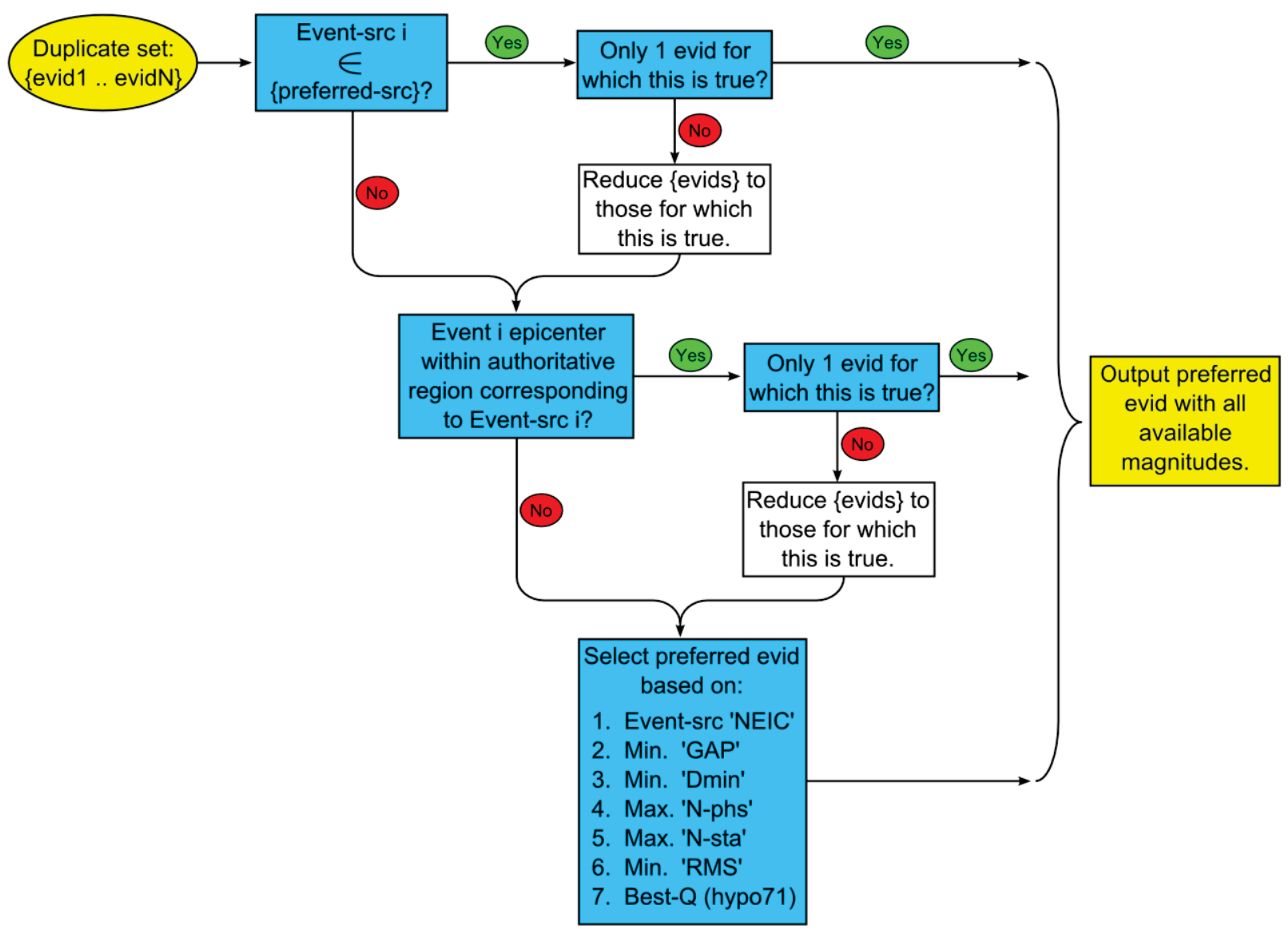

Figure 4.1 - Flowchart showing the logic used in selecting a preferred event from a list of redundant events for the concatenated file of all input catalogs. 


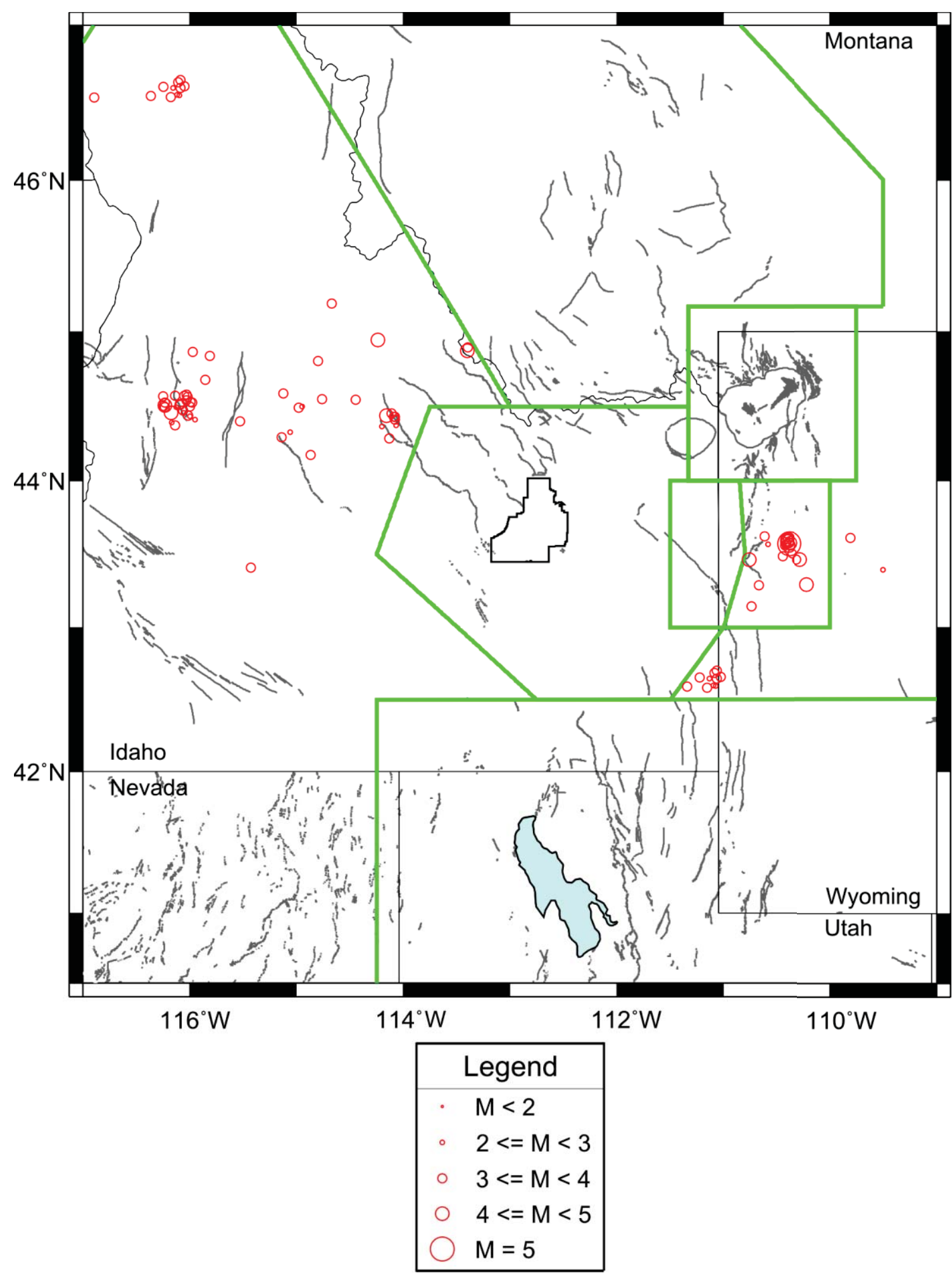

Figure 4.2 - Map of all events whose location sources were NEIC and that were selected as the preferred event from a set of redundant events. Also plotted are the authoritative regions from figure 3.2 for reference. Other symbols are as in figure 2.1. 


\section{The Final Compilation: INL1850-2007}

The final INL1850-2007 compilation was output from the duplicate search (see Section 4), formatted as in Table 3.10. After the duplicate-search was performed and non-preferred, redundant events removed, the 75,099 remaining events make up the INL1850-2007 compilation, with magnitude type counts as in Table 5.1, used in the sensitivity analyses. The map in figure 5.1 shows the earthquakes in the compilation. Maps in figure 5.2 plot subsets of the compilation by magnitude.

This compilation achieved the purpose of creating an updated regional earthquake catalog for use in the SAEP sensitivity analyses. It incorporated all known seismicity in the region from the years 1850 through 2007 with obvious, redundant events removed while preserving all unique magnitude information for each event. Prior to performing detailed focal depth analysis, depth datums should be verified (Section 3.1.1). However, this catalog can be used for showing the distribution of seismicity within the $200 \mathrm{mi}(322 \mathrm{~km})$ radius of the INL. Further, this catalog was then used in the sensitivity analysis where further processing steps were undertaken to produce an updated catalog with uniform moment magnitudes $\left(\mathrm{M}_{\mathrm{w}}\right)$, declustering for dependent events, and evaluation of completeness over the time period of the catalog. 
Table 5.1. INL1850-2007 magnitude type occurrences

\begin{tabular}{|l|l|}
\hline Magnitude type & Number of occurrences \\
\hline $\mathrm{Mw}$ & 130 \\
\hline $\mathrm{Ms}$ & 9 \\
\hline $\mathrm{mb}$ & 694 \\
\hline $\mathrm{ML}$ & 11703 \\
\hline $\mathrm{Md}$ & 97519 \\
\hline $\mathrm{MN}$ & 14 \\
\hline $\mathrm{MI}$ & 66 \\
\hline FA & 11 \\
\hline $\mathrm{UK}$ & 230 \\
\hline
\end{tabular}




\section{Earthquakes from 1850 - 2007}



Figure 5.1 - Map of the INL1850-2007 earthquake compilation used in the SAEP sensitivity analysis. Epicenters are scaled by magnitude. 


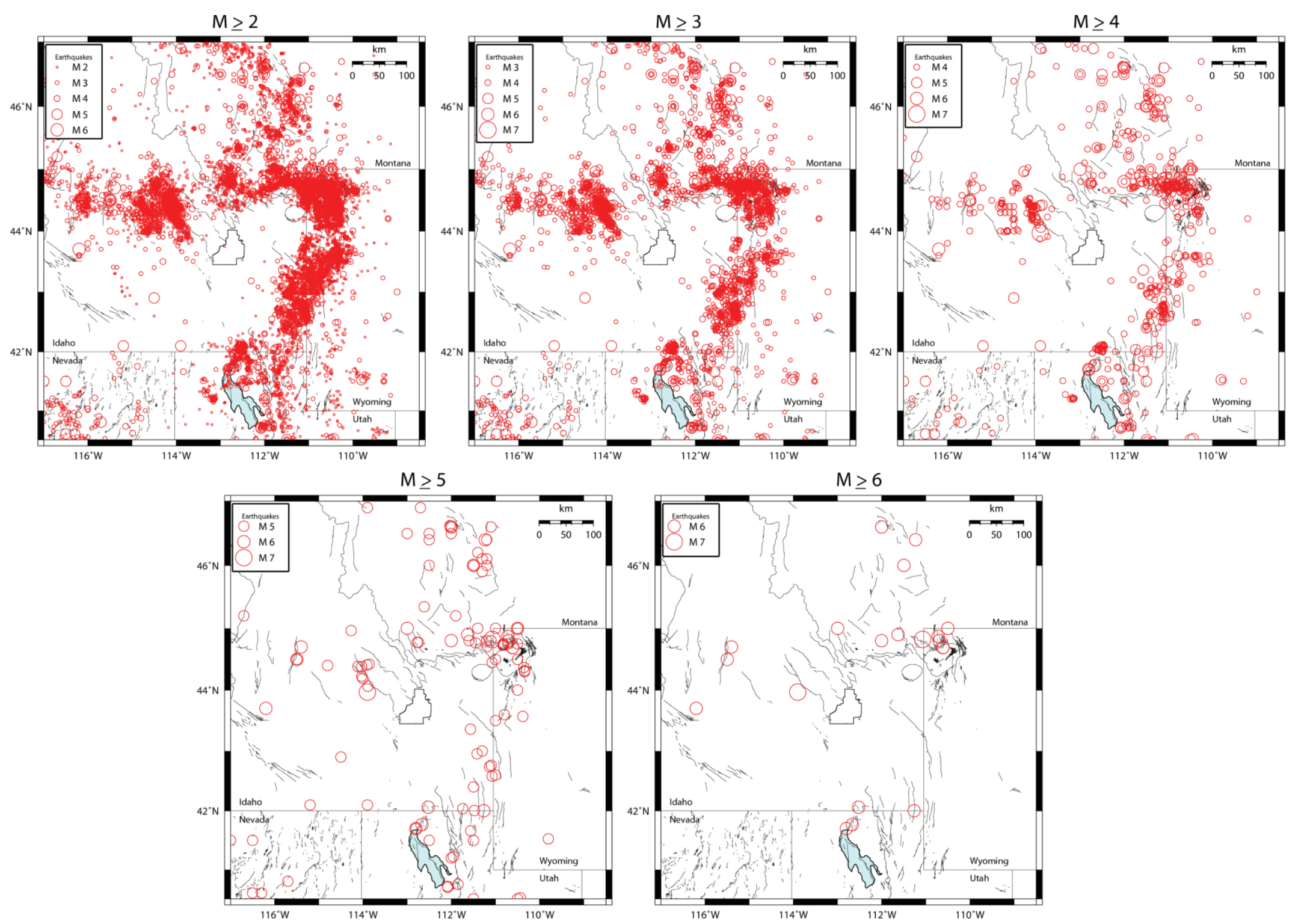

Figure 5.2 - Maps of the INL1850-2007 earthquake compilation subdivided by magnitude. Plot subtitles indicate the magnitude ranges of the events included in the plots. 


\section{References}

ANSS, 2009a, Advanced National Seismic System, http://www.ncedc.org/anss/.

ANSS, 2009b, Advanced National Seismic System, http://www.ncedc.org/anss/anss-detail.html.

Askew, B. and S.T. Algermissen, 1983, An earthquake catalog for the Basin and Range Province 18031977, U.S. Geological Survey Open-File Report 83-86, 40 pp.

Basham, P.W., D.H. Weichert, and M.J. Berry, 1979, "Regional assessment of seismic risk in Eastern Canada," Bull. Seismol. Soc. Am., Vol. 69, pp. 1567- 1602.

Berg, J.W., Jr. and C.d. Baker, 1963, “Oregon earthquakes, 1841 through 1958,” Bull. Seismol. Soc. Am., Vol. 53, pp. 95-108.

Bolt, B.A., 1984, “The magnitudes of the Hebgen Lake 1959 and Idaho 1983 earthquakes,” abs., Earthquake Notes, Vol. 55, p. 13.

Brumbaugh, D.A., 2001, The 1994 Draney Peak, Idaho, earthquake sequence: Focal mechanisms and stress field inversion, M.S. Thesis: University of Utah, Salt Lake City, Utah, 157 pp.

Carver, D., W.D. Richind, and C.J. Langer, 1983, "Details of the aftershock process following the 30 September 1977 Uinta Basin, Utah, earthquake,” Bull. Seismol. Soc. Am., Vol. 73, pp. 435-448.

CVO, 2009, Cascades Volcano Observatory, http://vulcan.wr.usgs.gov/Volcanoes/Yellowstone/description yellowstone.html.

Dewey, J.W., 1987, “Instrumental seismicity of central Idaho,” Bull. Seismol. Soc. Am., Vol. 77, pp. 819836.

Doser, D.I. and R.B. Smith, 1989, "An assessment of source parameters of earthquakes in the Cordillera of the western United States," Bull. Seismol. Soc. Am., Vol. 79, pp. 1383-1409.

Earthscope, 2010, USArray Transportable Array Seismic Network, http://www.earthscope.org/observatories/usarray.

Eaton, J.P., M.E. O’Neill, and J.N. Murdock, 1970, “Aftershocks of the 1966 Parkfield-Cholame, California, Earthquake: A Detailed Study,”Bull. Seismol. Soc. Am., Vol. 60, pp. 1151-1197.

Farrell, J. (farrell@earth.utah.edu),2009, “Yellowstone and Teton Earthquake Catalogs,” N. Seth Carpenter (seth.carpenter@inl.gov), July 1, 2009.

Gutenberg, B. and C.F. Richter, 1965, Seismicity of the Earth and Associated Phenomena, Princeton: Princeton University Press, 1954, 2nd ed.

CMT, 2010, The Harvard Centroid Moment Tensor Catalog, http://www.globalcmt.org/CMTsearch.html.

Husen, S. and R.B. Smith, 2004, "Probabilistic Earthquake Relocation in Three-Dimensional Velocity Models for the Yellowstone National Park Region, Wyoming," Bull. Seismol. Soc. Am., Vol. 94, pp. 880-896.

Jones, A.E., 1975, Bulletin of the Seismological Laboratory: Recording of earthquakes at Reno, 19161951, Univ. of Nevada Report.

Jackson S.M., and J.E. Zollweg, 1988, "Seismic studies of an earthquake sequence in the White Cloud Peaks, Idaho," abs., Seism. Res. Lett. Vol. 59, p. 6.

Kanamori, H. and P.C. Jennings, 1978, "Determination of local magnitude ML from strong motion accelerograms," Bull. Seismol. Soc. Am., Vol. 68, pp. 471-485. 
Klein, F.W., 2002, User's guide to HYPOINVERSE-2000, a Fortran program to solve for earthquake locations and magnitudes, U.S. Geological Survey Open-File Report, 02-171.

Lee, W.H.K. and J.C. Lahr, 1975, HYPO71 (Revised), A computer program for determining hypocenter, magnitude, and first motion pattern of local earthquakes, U.S. Geological Survey Open-File Report 75-311, 113 pp.

NEIC, 2009a, National Earthquake Information Center, http://neic.usgs.gov/neis/epic/epic rect.html.

NEIC, 2009b, National Earthquake Information Center, http://neic.usgs.gov/neis/epic/sr_format.html.

O’ Connell, D.R.H., C. Wood, D.A. Ostenaa, L. Block, R. LaForge, 2003, Ground Motion Evaluation for Jackson Lake Dam - Minidoka Project, Wyoming, Bureau of Reclamation, Seismotectonics and Geophysics Group, Report 2003-2.

Payne, S.J., J.E. Zollweg, and D.W. Rodgers, 2004, "Stress Triggering of Conjugate Normal Faulting: Late Aftershocks of the 1983 Ms 7.3 Borah Peak, Idaho, Earthquake," Bull. Seismol. Soc. Am., Vol. 94, pp. 828-844.

Payne, S.J., N.S. Carpenter, J.M. Hodges, and R.G. Berg, 2008, INL Seismic Monitoring Annual Report: January 1, 2007 - December 31, 2007, INL/EXT-08-14712.

Pechmann, J.C. (pechmann@seis.utah.edu), 2009, “catalog/data request,” N. Seth Carpenter (seth.carpenter@inl.gov), February 2, 2009.

PNSN, 2009, Pacific Northwest Seismic Network, http://www.pnsn.org/welcome.html.

Rasmussen, N., 1966, Seismology report on Washington, Idaho and Northern California and the Hanford Area, Washington, Douglas Nuclear Inc.

Richins, W.D., J.C. Pechmann, R.B. Smith, C.J. Langer, S.K. Goter, J.E. Zollweg, and J.J. King, 1987, "The 1983 Borah Peak, Idaho, earthquake and its aftershocks," Bull. Seismol. Soc. Am., Vol. 77, pp. 694-723.

Richins,W.D., R.B. Smith, C.J. Langer, J.E. Zollweg, J.J. King, and J.C. Pechmann, 1985, The 1983 Borah Peak, Idaho Earthquake: Relationship of Aftershocks to the Main Shock, Surface Faulting, and Regional Tectonics, U.S. Geological Survey Open-File Report 85-290, pp. 285-310.

Schafer, A.L. and S.J. Payne, 2009, Technical Approach For Sensitivity Analyses As Recommended By The Seismic Evaluation Team To Evaluate INL Probabilistic Seismic and Hazard Analyses, INL/MIS-09-16093, $38 \mathrm{pp}$.

Slemmons D.B., A.E. Jones, and J.I. Gimlet, 1965, “Catalogue of Nevada earthquakes, 1852-1960,” Bull. Seismol. Soc. Am., Vol. 55, pp. 519-565.

Stickney, M., 2006, Montana Seismicity Report for 2004, Montana Bureau of Mines and Geology.

Stickney, M. (MStickney@mtech.edu),2009, “catalog/data request,” N. Seth Carpenter (seth.carpenter@inl.gov), February 2, 2009.

Terra, F., 2009a, URS Corporation, Personal communication with N.S. Carpenter.

Terra, F., 2009b, URS Corporation, Personal communication with S.J. Payne.

UUSS-UU, 2009, University of Utah Utah Region earthquake catalog, http://www.quake.utah.edu/EQCENTER/LISTINGS/utCatalog.htm.

UUSS-WY, 2009, University of Utah Yellowstone earthquake catalog, http://www.quake.utah.edu/EQCENTER/LISTINGS/OTHER/yellCatalog.htm. 
White, B.J.P., 2006, Seismicity, Seismotectonics and Preliminary Earthquake Hazard Analysis of the Teton Region, Wyoming, M.S. Thesis: University of Utah, Salt Lake City, Utah, 186 pp.

White, B.J.P., R.B. Smith, S. Husen, J. Farrell, and I. Wong, 2009, "Seismicity and Earthquake Hazard Analysis of the Teton-Yellowstone Region, Wyoming," J. Volcanol. Geotherm. Res.,Vol. 188, pp. 277-296.

Woodward-Clyde Consultants, 1990, Earthquake strong ground motion estimates for Idaho National Engineering Laboratory, Final Report Volume I: Summary; Volume II - Methodology and Analyses; Volume III - Appendices, EG\&G Idaho Inc., Informal Report EGG-BG-9350, November 1990.

Wong, I. (Ivan_Wong@urscorp.com), 2010, “INL earthquake compilation report review,” N. Seth Carpenter (seth.carpenter@inl.gov), June 16, 2010.

Woodward-Clyde Consultants, 1992, Paleoseismic investigations of the southern Lemhi Fault, Idaho, EG\&G Informal Report EGG-GEO-10178, 32 pp. plus figures and tables.

Woodward-Clyde Federal Services, Geomatrix Consultants, and Pacific Engineering and Analysis, 1996, Site-Specific Probabilistic Seismic Hazard Analyses for the Idaho National Engineering Laboratory, Lockheed Idaho Technologies Company, Technical Report INEL-95/0536, 2 Volumes, May 1996.

Woolard, G.P., 1968, A catalogue of earthquakes in the U.S. prior to 1925, Hawaii Institute of Geophysics, University of Hawaii.

Wright, A. (amyw@ess.washington.edu),2008, “catalog/data request,” N. Seth Carpenter (seth.carpenter@inl.gov), December 27, 2008.

Wright, A. (amyw@ess.washington.edu),2009, “Quality factor info,” N. Seth Carpenter (seth.carpenter@inl.gov), June 2, 2009.

Zollweg, J.E., 1994, Personal Communication with S.J. Payne.

Zollweg, J.E and W.D. Richins, 1985, Later Aftershocks of the 1983 Borah Peak, Idaho, Earthquake and Related Activity in Central Idaho, U.S. Geological Survey Open-File Report 85-290, pp. 345 - 367. 